\title{
A fluorimetric study of the
} thorium-morin system

By Robert G. Milkey and Mary H. Fletcher

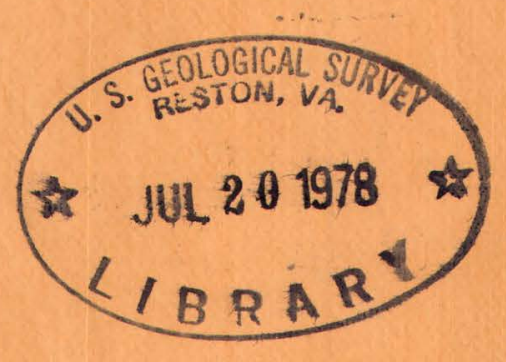

\section{Trace Elements Investigations Report 589}

UNITED STATES DEPARTMENT OF THE INTERIOR GEOLOGICAL SURVEY 


\section{Chemistry}

UNITED STATES DEPARTMENT OF THE INTERIOR

GEOLOGICAL SURVEY

A FLUORIMETRIC STUDY OF THE THORIUM-MORIN SYSTEM*

By

Robert G. Milkey and Mary H. Fletcher

April 1956

Trace Elements Investigations Report 589

This preliminary. report is distributed without editorial and technical review for conformity with official standards and nomenclature. It is not for public inspection or quotation.

*This report concerns work done on behalf of the Division of Raw Materials of the U. S. Atomic Energy Commission. 
USGS - TEI-589

\section{CHEMISTRY}

Distribution

No. of copies

Argonne National Laboratory .......................... 1

Atomic Energy Commission, Washington ................... 2

Division of Raw Materials, Albuquerque .................... I

Division of Raw Materials, Austin ...................... I

Division of Raw Materials, Casper ........................ I

Division of Raw Materials, Denver ........................ I

Division of Raw Materials, Ishpeming ..................... I

Division of Raw Materials, Phoenix ....................... 1

Division of Raw Materials, Rapid City ..................... I

Division of Raw Materials, Salt Lake City .................. I

Division of Raw Materials, Spokane ...................... I

Division of Raw Materials, Washington ..................... 3

Exploration Division, Grand Junction Operations Office ....... I

Grand Junction Operations Office ....................... I

Technical Information Service Extension, oak Ridge ......... 6

Tennessee Valley Authority, Wilson Dam ................... I

U. S. Geological Survey:

Fuels Branch, Washington ............................. I

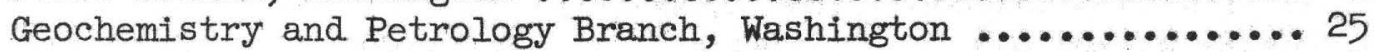

Geophysics, Branch, Washington ......................... 1

Mineral Deposits Branch, Washington ....................... I

P. C. Bateman, Menlo Park ............................... I

A. L. Brokaw, Grand Junction .............................. 1

N. M. Denson, Denver ............................... 1

R. L. Griggs, Albuquerque .......................... I

W. R. Keefer, Laramie ................................ I

L. R. Page, Washington ............................. I

P. K. Sims, Denver ................................. 1

Q. D. Singewald, Beltsville ........................... 1

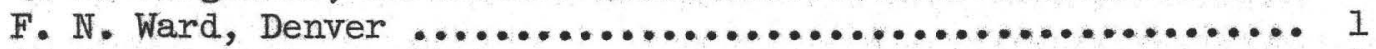

A. E. Weissenborn, Spokane ........................... I

TTEPO, Denver ..................................... 2

TEPCO, RPS, Washington, (including master) $\ldots \ldots \ldots \ldots \ldots \ldots \ldots . \ldots \ldots$ 
CONTENTS

Page

Abstract $\ldots \ldots \ldots \ldots \ldots \ldots \ldots \ldots \ldots \ldots \ldots \ldots \ldots \ldots \ldots \ldots \ldots \ldots \ldots \ldots \ldots \ldots \ldots \ldots \ldots \ldots$

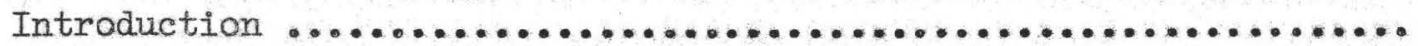
Characteristics of thorium-morin system $\ldots \ldots \ldots \ldots \ldots \ldots \ldots \ldots \ldots \ldots$

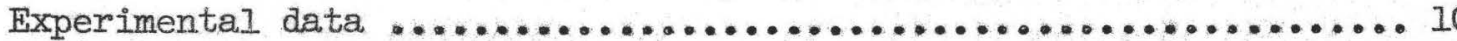

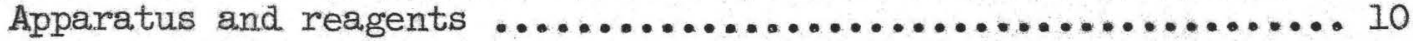
Transmission fluorimeter ............................ 10

Source of exciting light ........................ 10

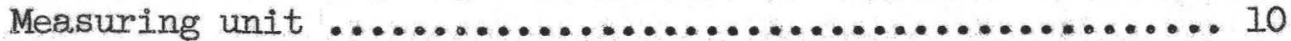

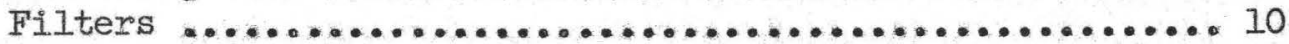

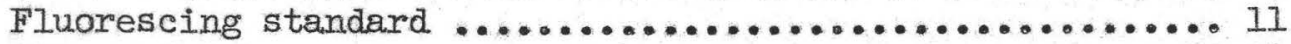

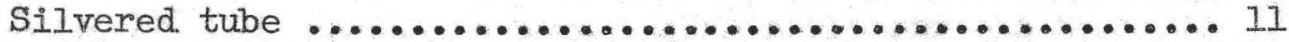

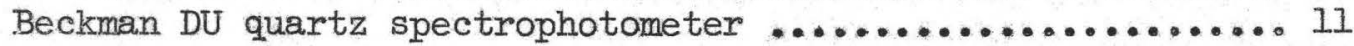

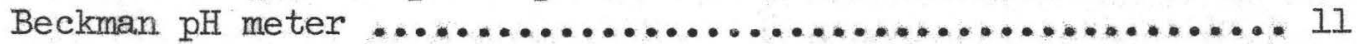

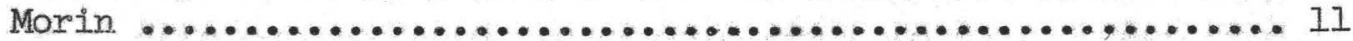

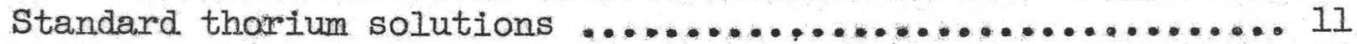

Materials tested as possible interferences ............... 12

Effect of experimental variables on fluorescence .............. 12

Acidity ........................................... 12

Alcohol ........................................... 12

Concentration of morin .............................. 12

Temperature ...................................... 17

Time of standing .................................... 17

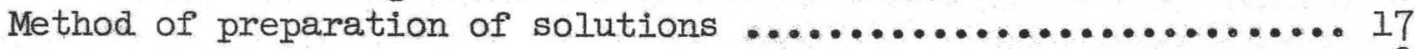

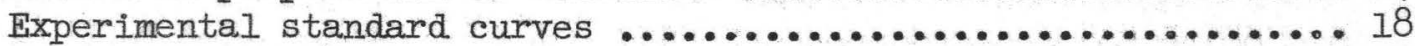

Comparison of fluorimetric and spectrophotometric methods ..... 22

Effect of other ions .................................... 22

Basic theory of fluorescence: Application to thorium-morin

system ............................................. 24

Derivation of the general equation $\ldots \ldots \ldots \ldots \ldots \ldots \ldots \ldots \ldots \ldots \ldots . \ldots \ldots$

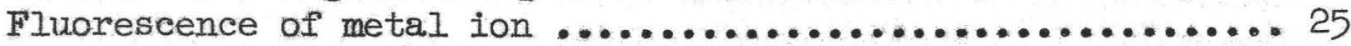

Fluorescence of reagent ............................. 27

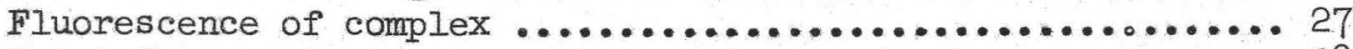

Total fluorescence .................................. 28

Application to simplified systems ...................... 29

Study of the fluorescence of the thorium-morin system ......... 30

Effect of the concentration of excess thorium .............. 31

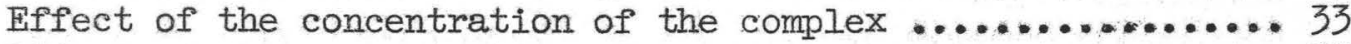

Effect of the concentration of uncombined morin ........... 37

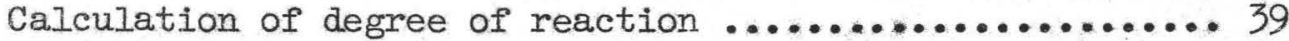

Determination of quenching by uncombined morin .......... 39

Calculation of optimum morin concentration ............. 42

Calculation of standard curve ............................ 46

Literature cited ....................................... 47

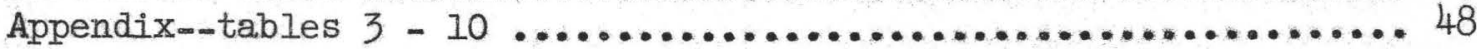


IILUSTRATIONS

Page

Figure 1. Absorption spectra for pure morin (A) and thorium-morin

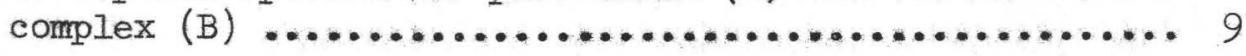

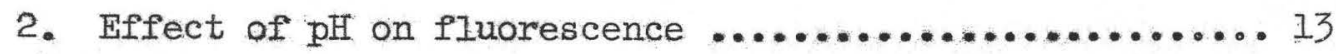

3. Effect of alcohol concentration on the fluorescence .... 14

4. Effect on fluorescence of adding increasing amounts of marin to a constant amount of $\mathrm{ThO}_{2}$ (50.3 micrograms);

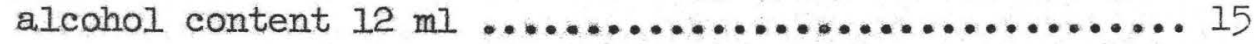

5. Effect on fluorescence of adding increasing amounts of morin to a constant amount of thorium ............... I6

6. Standard fluorescence curves, total morin 100 micrograms

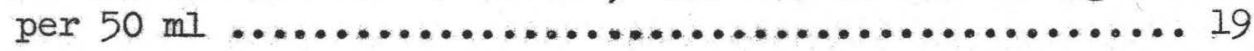

7. Standard fluorescence curves, total morin 165 micrograms

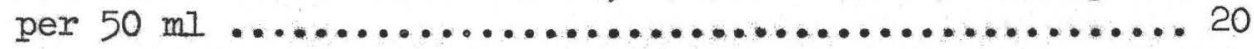

8. Experimental standard curves ...................... 21

9. Effect on fluorescence of adding increasing amounts of thorium to a constant amount of morin .............. 32

10. Fluorescence of complex as a function of the fraction

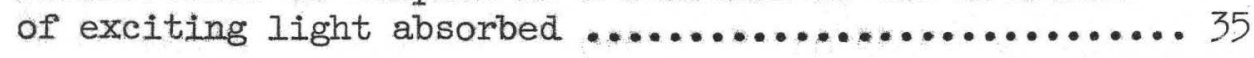

11. Fraction of total thorium converted to complex as a function of uncombined morin in solution .............40

12. Fraction of fluorescence remaining unquenched as a function of uncombined morin ..................... 43

13. Calculated fluorescence as a function of uncombined morin in the solutions 45

\section{TABIES}

Page

Table 1. Summary of the reactions of other ions with morin ...... 23

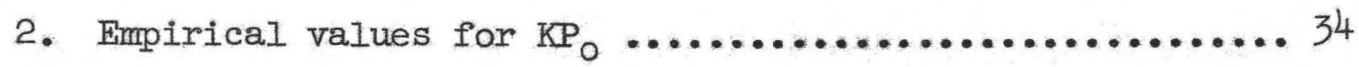


Table 3. Absorptivity values for morin and the complex ......... 49

4. Fraction of total $\mathrm{ThO}_{2}$ (50.3 micrograms) in the form of complex, when concentration of morin ranges from $0-4000$

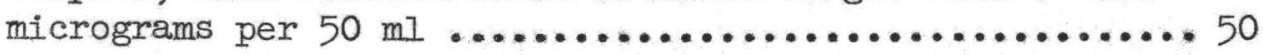

5. Fraction of total fluorescence remaining unquenched when 50.3 micrograms $\mathrm{ThO}_{2}$ is mixed with amounts of morin ranging from 0-600 micrograms per $50 \mathrm{ml}$ ( $2 \mathrm{ml}$ of alcohol

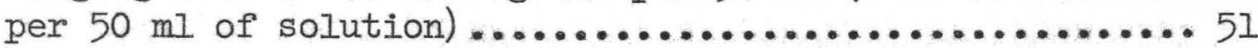

6. Fraction of total fluorescence remaining unquenched when 50.3 micrograms $\mathrm{ThO}_{2}$ is mixed with amounts of morin. ranging from $0-4000$ micrograms per $50 \mathrm{ml}$ of solution ( $12 \mathrm{ml}$ of alcohol per $50 \mathrm{ml}$ of solution) .............. 52

7. Calculated fluorescence for solutions containing a total of 50.3 micrograms $\mathrm{ThO}_{2}$ and amounts of morin ranging from $50-200$ micrograms per $50 \mathrm{ml}$ ( $2 \mathrm{ml}$ of alcohol per $50 \mathrm{ml}$

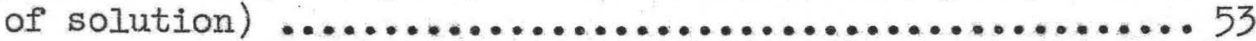

8. Calculated fluorescence for solutions containing a total of 15 micrograms of $\mathrm{ThO}_{2}$ and amounts of morin ranging from 50-200 micrograms per $50 \mathrm{ml}$ ( $2 \mathrm{ml}$ of alcohol per

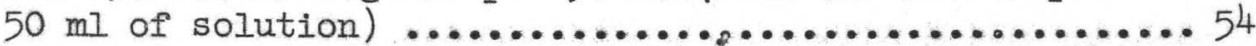

9. Calculations of complex formed (micrograms per $50 \mathrm{ml}$ ) for solutions containing (a) a total of 100 micrograms morin and $\mathrm{ThO}_{2}$ ranging from 10-60 micrograms, (b) a total of 165 micrograms morin and $\mathrm{ThO}_{2}$ ranging from $10-90$ micrograms

10. Calculated fluorescence for standard curves--100-165 micrograms of morin per $50 \mathrm{ml}(2 \mathrm{ml}$ of alcohol per $50 \mathrm{ml}$ of solution) 


\section{A FLUORIMETRIC STUDY OF THE THORIUM-MORIN SYSTEM}

By Robert G. Milkey and Mary H. Fletcher

\section{ABSTRACT}

Thorium reacts with morin to yield a yellow complex that fluoresces when irradiated with ultraviolet light. The effect on the fluorescence of such variables as concentration of acid, alcohol, thorium, morin, and complex; time, temperature, and wavelength of exciting light are studied. to determine experimental conditions yielding maximum fluorescence. The effects of $\mathrm{Zr}^{4+}, \mathrm{Al}^{3+}, \mathrm{Fe}^{3+}, \mathrm{Ca}^{2+}$, and $\mathrm{La}^{3+}$ are discussed.

The fundamental relationships between light absorption and fluorescence are expressed in a general equation which appiies to a three-component system when the fluorescence is measured in a transmission-type fluorimeter. This general equation is used to obtain an expression for the fluorescence of the thorium-morin system.

Equations, derived from experimental data, relate both the fraction of thorium reacted to form complex and the fraction of unquenched fluorescence to the concentration of uncombined morin. These functions, when combined with the general equation, give an expression which relates the total net fluorescence to the amount of uncombined morin in the solution. This last equation can be used to determine the one region for the concentration of uncombined morin that gives maximum sensitivity for the system. Calculated standard curves are in excellent agreement with experimental curves. 


\section{INTRODUCTION}

Morin reacts with thorium in weakly acid solutions $(3,4,7,8)$ to form a stable yellow complex which fluoresces yellow-green when its solu. tions are irradiated. with ultraviolet light. Both the color and fluorescence of this complex have been investigated.

The results of the spectrophotometric study have been presented in an earlier paper (2) which evaluates the color system as a basis for the quantitative determination of trace amounts of thorium.

This paper evaluates the fluorescent system as a basis for the quantitative determination of trace amounts of thorium. Some of the theoretical and mathematical relationships between fluorescence and light absorption, as exhibited in the thorium-morin system, are also included. This report is part of a program conducted by the U. S. Geological Survey on behalf of the Division of Raw Materials of the U. S. Atomic Energy Commission.

\section{CHARACTERISTICS OF THORIUM-MORIN SYSTEM}

The reaction between thorium and morin occurs in slightly acid solution according to the equation

$$
\operatorname{ThX} \mathrm{X}_{4}+2 \mathrm{M} \cdot \mathrm{H} \rightleftharpoons \mathrm{ThM}_{2} \mathrm{X}_{2}+2 \mathrm{HX}
$$

where $\mathrm{M} \cdot \mathrm{H}$ is morin (5, 7, 2', 4' flavanol) having the structure

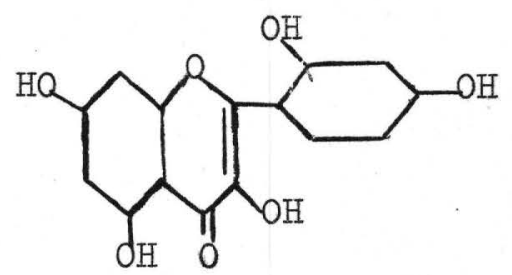

and $\mathrm{X}$ is a univalent negative ion such as $\mathrm{Cl}^{-}$or $\mathrm{NO}_{3}{ }^{-}$. The reaction is instantaneous and results in the formation of a single, yellow, stable complex having a molar ratio of Th:M of $1: 2$. 
The equilibrium constant for the reaction, according to the equation

$$
\mathrm{K}_{\text {equil. }}=\frac{\left[\mathrm{ThM}_{2}^{+2}\right]\left[\mathrm{H}^{+}\right]^{2}}{\left[\mathrm{Th}^{+4}\right][\mathrm{M} \cdot \mathrm{H}]^{2}}
$$

is approximately $1 \times 10^{6}$ (2).

Solutions of the complex fluoresce a bright green when irradiated with long wavelength ultraviolet light $(3,4,7,8)$. The wavelength band of the fluorescent light ranges from approximately 488 to $555 \mathrm{m \mu}$, with peak intensity between 513 and $533 \mathrm{m \mu}$, as determined by visual inspection with a spectroscope (personal communication, H. Jaffe, U. S. Geological Survey, and C. E. White, Univ. of Maryland).

Absorption spectra for solutions of the complex (curve B) and for pure morin (curve A) are presented in figure 1. The region between the dotted lines in this figure indicates the wavelength band of the fluorescent light. It should be noted that the fluorescence occurs in that part of the spectrum in which light is transmitted completely by both the complex and morin. Moreover, solutions with thorium concentrations as large as $50 \mathrm{mg}$ ThO 2 per $50 \mathrm{ml}$ also completely transmit all light in this spectral region. The spectra indicate that light having a wavelength near 410 mu would be advantageous for the production of fluorescence, and such light (404.7 mu) was used to establish the experimental conditions. 


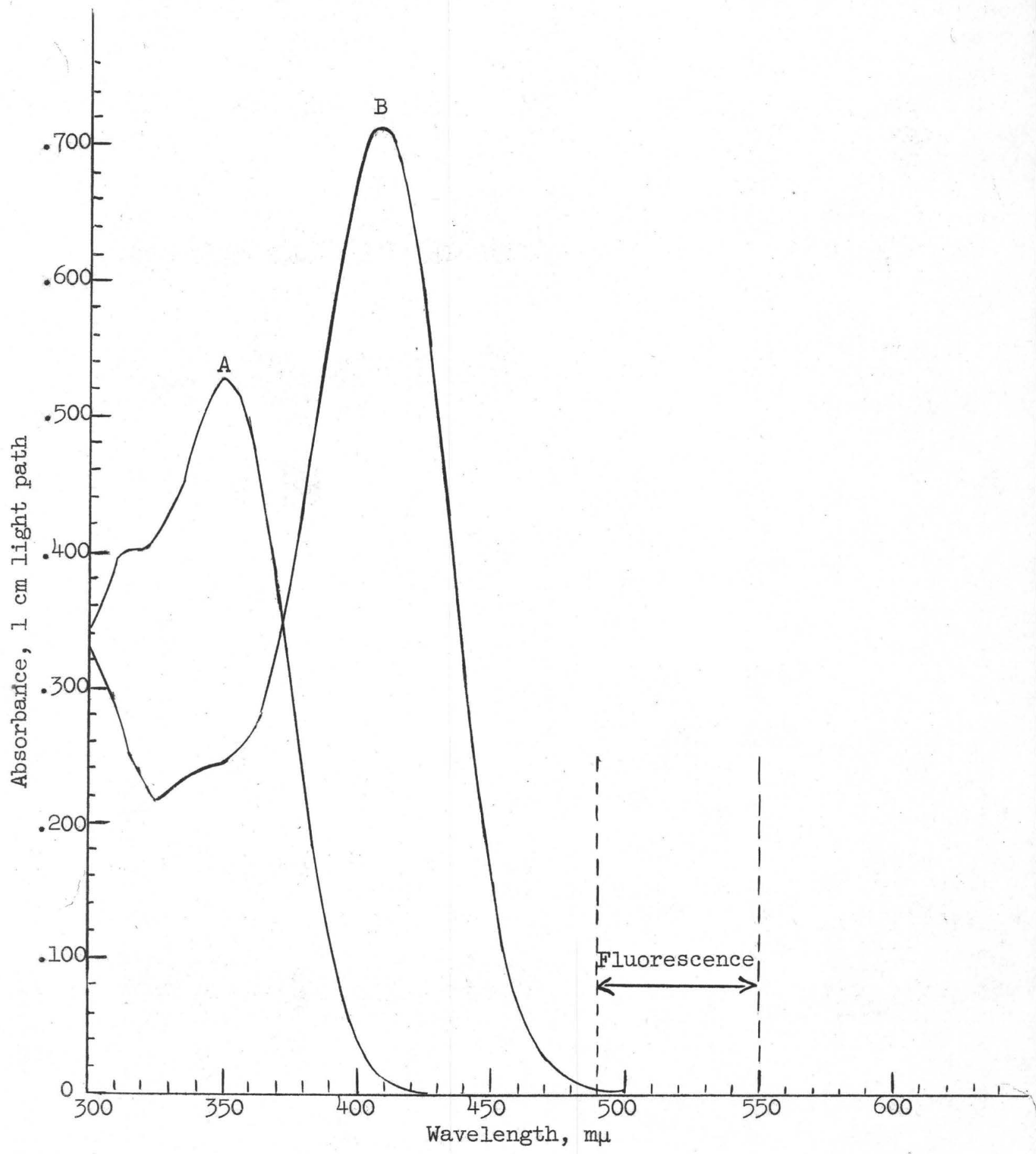

Figure 1.--Absorption spectra for pure morin (A) and thorium-morin complex (B) arrow indicates wavelength region of fluorescence. Curve A, 600 micrograms morin/50 ml of solution; curve $B, 600$ micrograms morin plus $2 \mathrm{mg} T \mathrm{ThO}_{2} / 50 \mathrm{ml}$ of solution; $2 \mathrm{ml}$ alcohol in each. 


\section{EXPERIMENTAL DATA}

\section{Apparatus and reagents}

\section{Transmission flluorimeter}

The transmission fluorimeter, especially built for this study, is arranged so that the light source, sample cell, and phototube are on a linear vertical axis, with lamp and phototube on opposite sides of the sample.

Source of exciting light.--An HH-4 high-pressure mercury lamp operated from a Sola no. 301,883 constant-wattage transformer and cooled with a dark-room ventilator. The lamp was 18 inches above the top of the solution cell. (Intensity of the light supplied at wavelength $404.7 \mathrm{m \mu}$ was approximately four times the intensity of the light at $365 \mathrm{m \mu}$ wavelength. Personal communication, C. L. Waring, U. S. Geological Survey*)

Measuring unit.--A IP2I multiplier phototube powered by a regulated high-voltage supply (Atomic Instrument Co., model 306) and used in conjunction with an ultrasensitive microammeter (RCA no. WV-84A). The measuring unit was used at the same sensitivity for all measurements in this study.

A potential of approximately 550 volts was always applied to the phototube. This resulted in standard deflections of 0.640 microampere for $P_{\mathrm{O}}(404.7 \mathrm{m \mu})$ and 0.980 microampere for $P_{\mathrm{O}}(365.0 \mathrm{m \mu})$, from the fluorescent uranium glass standard used for calibration.

\section{Filters.--Primary filters: 1. A combination of Corning filters} no. 3060,4308 , and 5970 was used to isolate light of wavelength $404.7 \mathrm{m \mu}$. 2. A combination of Corning filters no. 7380,5874 , and 5860 was used to isolate light of wavelength $365.0 \mathrm{m \mu}$. 
Secondary filters: Corning no. 4010 was used to isolate the fluorescent light.

Fluorescing standard.--Uranium glass was used to set instrument sensitivity.

Silvered tube.--A brass tube with silvered interior connected the phototube and sample compartments of the instrument. The phototube was at a distance of about 12 inches from the bottom of the sample cell.

Beckman DU quartz spectrophotometer

Beckman pH meter

Morin

Morin, $\mathrm{C}_{15} \mathrm{H}_{10} \mathrm{O}_{7} \cdot 2 \mathrm{H}_{2} \mathrm{O}$ (mol. wt. 338.26) of high purity, obtained from Dr. Theodor Schuchardt in Munich, Germany. Solutions of morin of the concentration desired were prepared by dissolving the solid material in 95 percent ethyl alcohol.

\section{Standard thorium solutions}

A stock solution of thorium chloride was prepared by dissolving the salt (reagent grade) in 3 percent hydrochloric acid. This solution, which contained $100 \mathrm{mg}$ of $\mathrm{ThO}_{2}$ per $\mathrm{ml}$, was standardized gravimetrically.

Working solutions were prepared from the stock solution by dilution with distilled water and, when necessary, by the addition of more acid. The acidity of all working solutions was adjusted to give a pH of 1.9 to 2.0. 
Materials tested as possible interferences

Stock solutions of the chlorides of aluminum, calcium, iron, lanthanum, and zirconium were prepared in hydrochloric acid solutions which were diluted as required to give working solutions of the proper concentration at a $\mathrm{pH}$ of 2.0. The working solutions were used immediately after dilution.

\section{Effect of experimental variables on fluorescence}

\section{Acidity}

The effect of acidity on the fluorescent system is shown in figure 2 . In curve B, which represents solutions similar to those found in routine analysis, the point of maximum fluorescence occurs at $\mathrm{pH} 2$, and this is also the point of maximum difference between the solutions and the blanks. Accordingly, a pH of 2 was chosen for the fluorimetric study.

\section{Alcohol}

The effect of alcohol on the fluorescence of solutions of complex, of complex and uncombined morin, and of morin alone is illustrated in figure 3 which shows that sensitivity increases with alcohol content until 20 to $25 \mathrm{ml}$ of alcohol are present per $50 \mathrm{ml}$ of solution.

\section{Concentration of morin}

The effect of morin concentration when the total $\mathrm{ThO}_{2}$ content of each solution is 50.3 micrograms per $50 \mathrm{ml}$ is shown in figures 4 and 5 . Maximum fluorescence is obtained from solutions containing 100 to 200 micrograms of morin per $50 \mathrm{ml}$. This holds true for other concentrations of $\mathrm{ThO}_{2}$ of the same order of magnitude. 


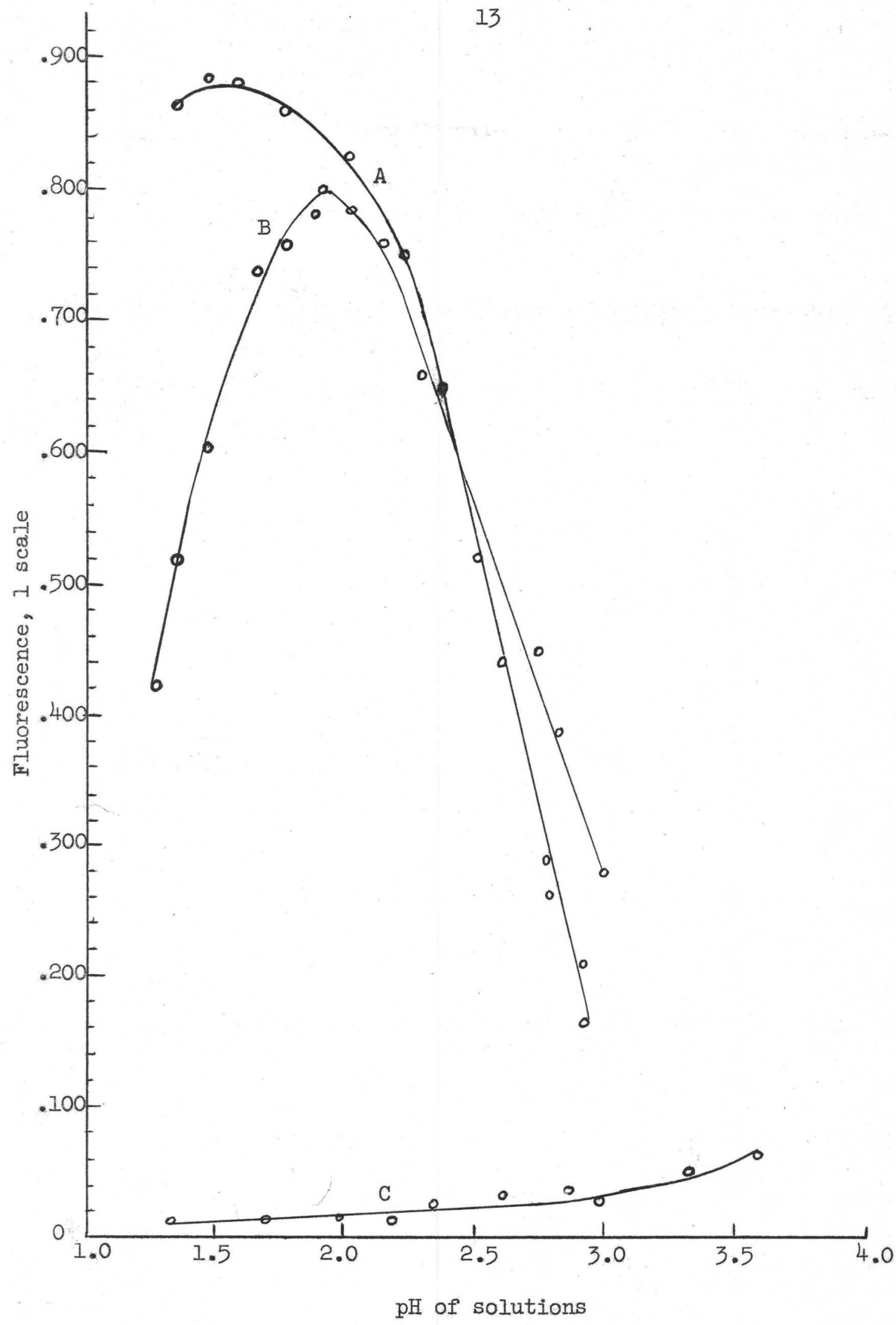

Figure 2.--Effect of $\mathrm{pH}$ on fluorescence. Curve A, complex (37.4 micrograms per $50 \mathrm{ml}$ ): curve B, mixture of complex plus uncombined morin (100.6 micrograms $\mathrm{ThO}_{2}$ plus 165 micrograms total morin per $50 \mathrm{ml}$ ); curve C, morin (300 micrograms per $50 \mathrm{ml}$ ); $2 \mathrm{ml}$ of alcohol in all solutions; $P_{O}$ (404.7 mu). 


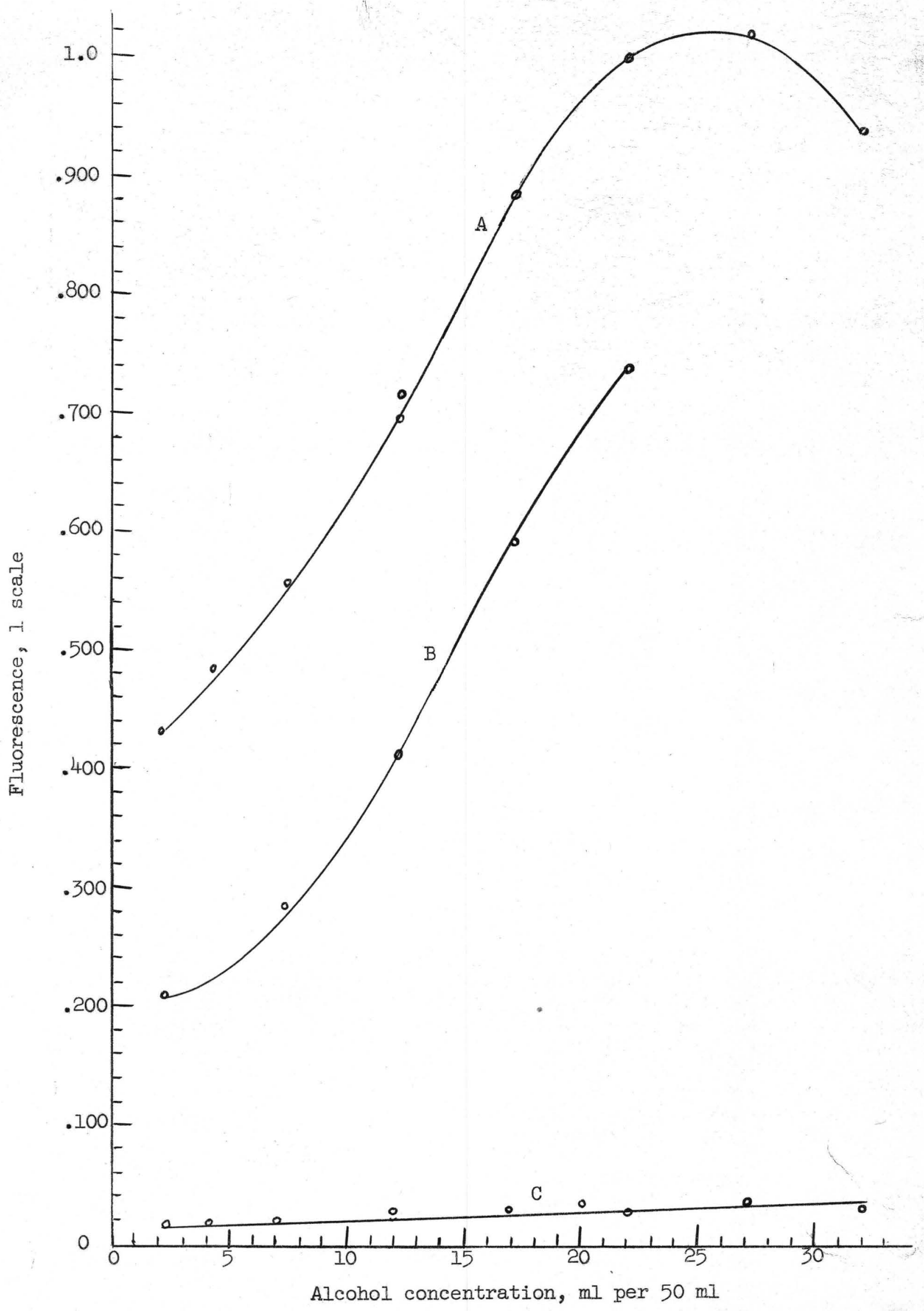

14

Figure 3.--Effect of alcohol concentration on the fluorescence. Curve $A_{\text {, }}$ complex ( 18.7 micrograms per $50 \mathrm{ml}$ ); curve $B$, mixture of complex plus uncombined morin (20.12 micrograms $\mathrm{ThO}_{2}$ plus 165 micrograms total morin per $50 \mathrm{ml}$ ); curve $\mathrm{C}$, morin (300 micrograms per $50 \mathrm{ml}$ ); $\mathrm{P}_{\mathrm{O}}$ ( $404.7 \mathrm{mit}$ ). 


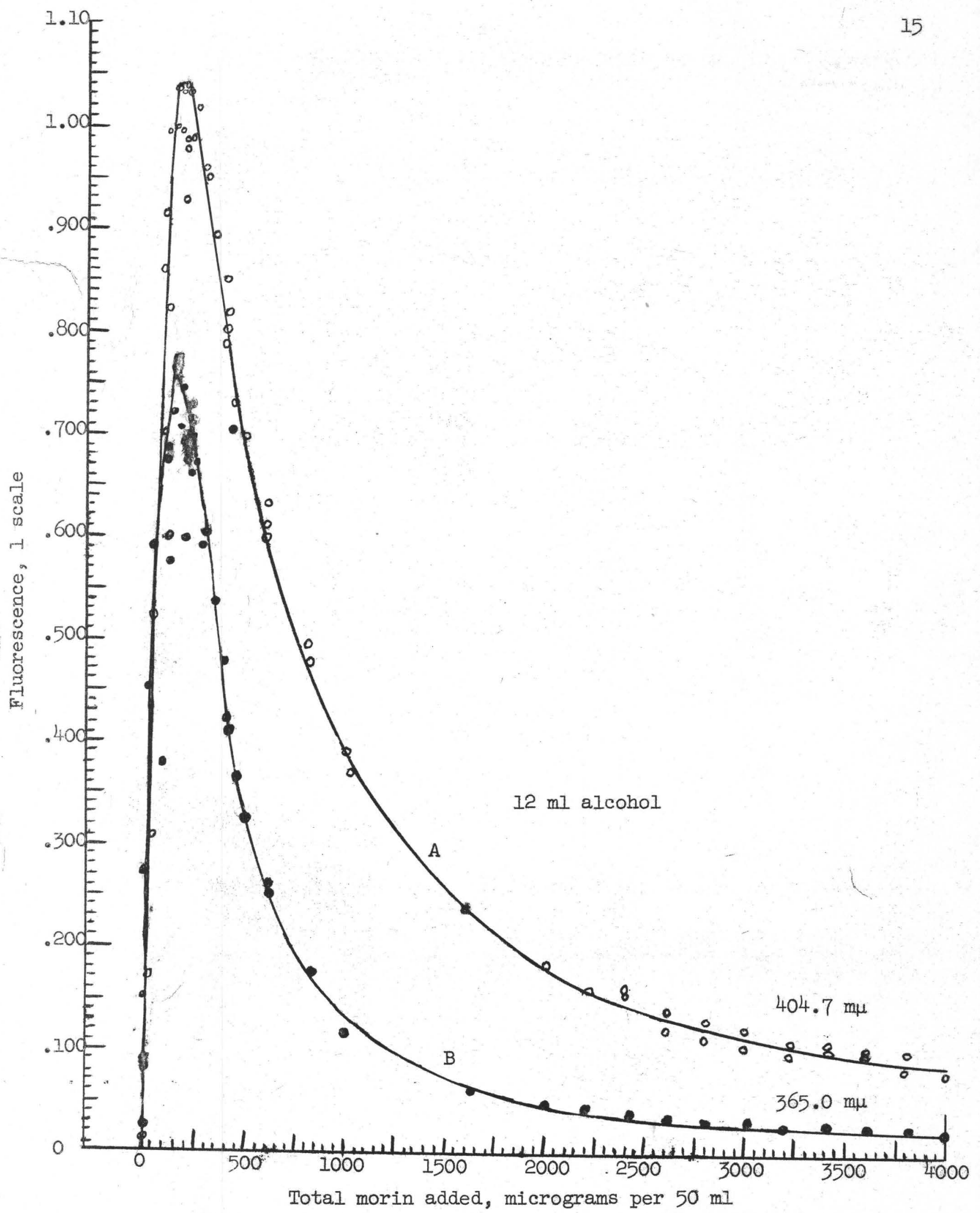

Figure 4.-.Effect on fluorescence of adding increasing amounts of morin to a constant amount of $\mathrm{ThO}_{2}(50.3$ micrograms per $50 \mathrm{ml})$; alcohol content $12 \mathrm{ml}$ per $50 \mathrm{ml} ; \mathrm{P}_{0}(404.7 \mathrm{m \mu})$. 


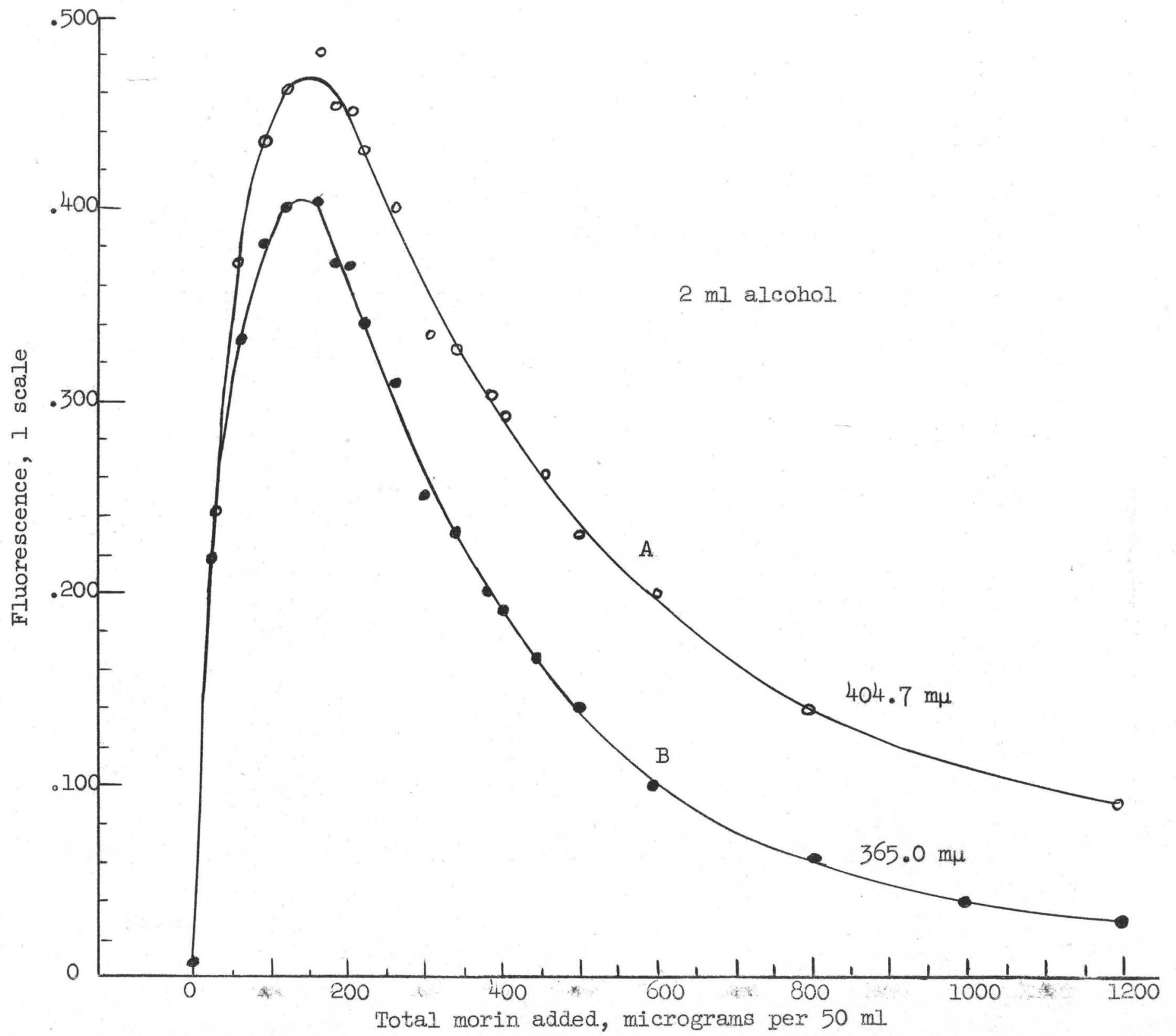

Figure 5.--Effect on fluorescence of adding increasing amounts of morin to a constant amount of thorium ( 50.3 micrograms $\mathrm{ThO}_{2}$ per $50 \mathrm{ml}$ ); alcohol content $2 \mathrm{ml}$ per $50 \mathrm{ml}: \mathrm{P}_{0}$ ( $404.7 \mathrm{m \mu}$ ). 
Temperature

The absorbance of the thorium-morin complex is only slightly affected. by temperature. However, in the temperature range from $10^{\circ}$ to $50^{\circ} \mathrm{C}$, the intensity of fluorescence decreases linearly with increasing temperature. The readings on a solution that contained 25.9 micrograms of complex per $50 \mathrm{ml}$ decreased 15 percent when the temperature was increased from $20^{\circ}$ to $30^{\circ} \mathrm{C}$

\section{Time of standing}

The fluorescence develops immediately and reproducible readings are obtained over a period of several hours. Typical of the reproducibility is a series of readings made at 30-minute intervals over a period of several hours on a solution that contained 46.6 micrograms of ThO 2 and 200 micrograms of morin per $50 \mathrm{ml}$. After the initial 30 minutes, the difference between. the highest and lowest readings was less than 2 percent.

\section{Method of preparation of solutions}

A11 of the solutions used in this study were prepared in 50-ml glass stoppered graduates or flasks. The procedure follows:

1. Add $1.0 \mathrm{ml}$ of $0.63 \mathrm{~N} \mathrm{HCl}$.

2. Add thorium solution that has a $\mathrm{pH}$ of 2.0 and contains no other metallic ions.

3. Adjust volume of solution to $20 \mathrm{ml}$ with distilled water. Mix.

4. Add $2.0 \mathrm{ml}$ of morin solution (weight of morin added will be indicated separately for each test). 
5. If total aleohol content of $12 \mathrm{ml}$ is desired, add $10 \mathrm{ml}$ of aleohol.

6. Mix.

7. Adjust volume to exactly $50 \mathrm{ml}$ with distilled water.

8. Stopper and mix well.

9. After half an hour, measure the fluorescence of a 25 -ml aliquot.

Experimenta.1 standard curves

Typical standard eurves are presented in figures 6 and 7 (solid lines) and in figure 8. The curves in figures 6 and 7 indicate that thorium concentrations ranging from 10 to 150 micrograms of $\mathrm{ThO}_{2}$ can be measured with good accuracy.

In figure 8 , however, which covers the thorium range most important to trace analysis and refers to a more sensitive instrument scale, the curves are not as well defined as those for the higher thorium range even though each point on the curves represents the average obtained from readings on four different solutions. In the linear portion of the curve obtained with an exciting wavelength of $404.7 \mathrm{~m} \mu$ in figure 8 , a difference in fluorescence readings of 0.100 is equivalent to 1.10 micrograms of $\mathrm{ThO}_{2}$. As the instrument can be read to a difference of 0.004 , the possibility of detecting a concentration difference of 0.044 microgram of $\mathrm{ThO}_{2}$ per $50 \mathrm{ml}$ is indicated. if the 0.1 instrument scale is used. Unfortunately it is impossible to take advantage of this sensitivity at present because random errors from unknown sources often occur; these amount to approximately \pm 0.5 microgram of $\mathrm{ThO}_{2}$ on the individual readings. 


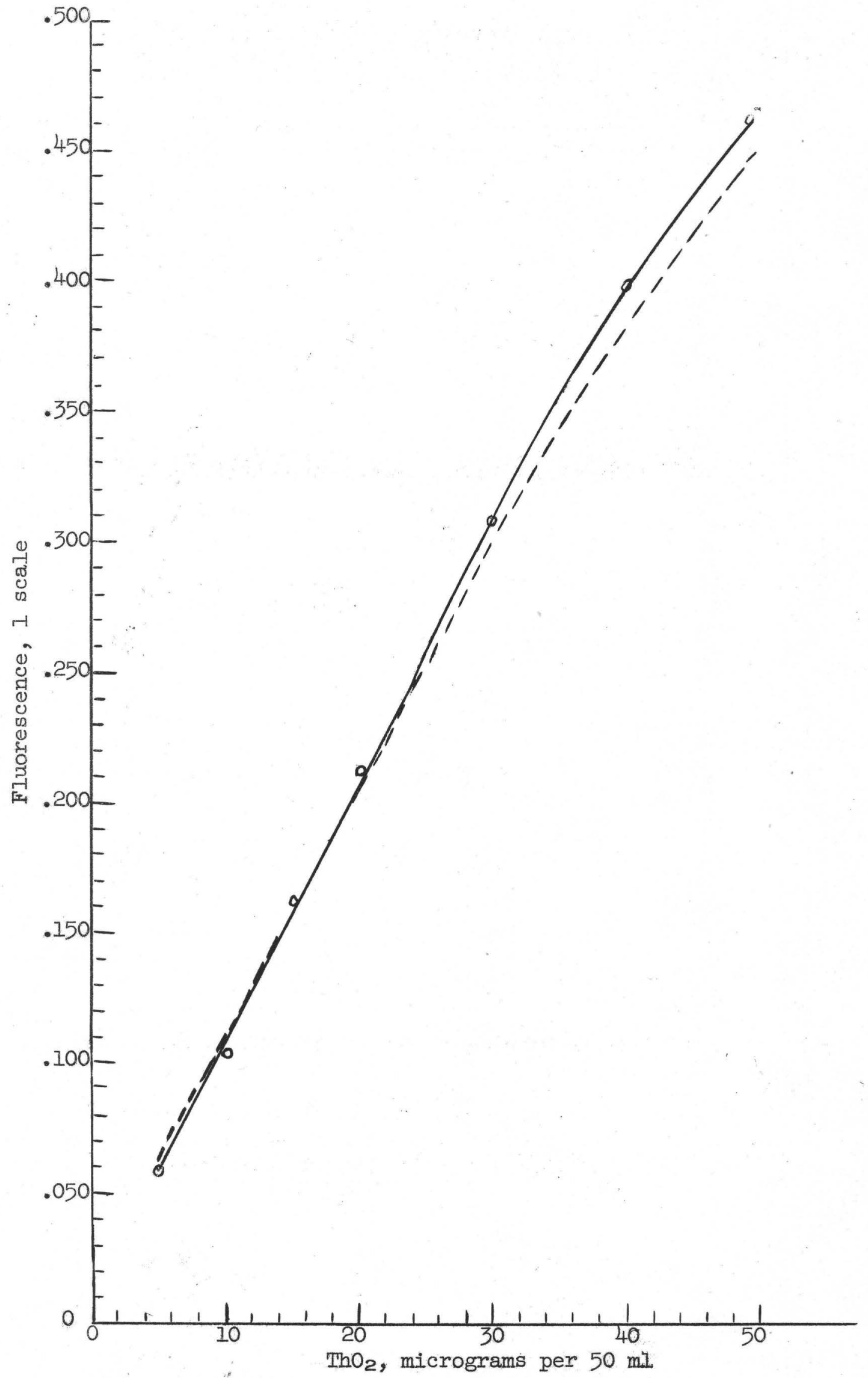




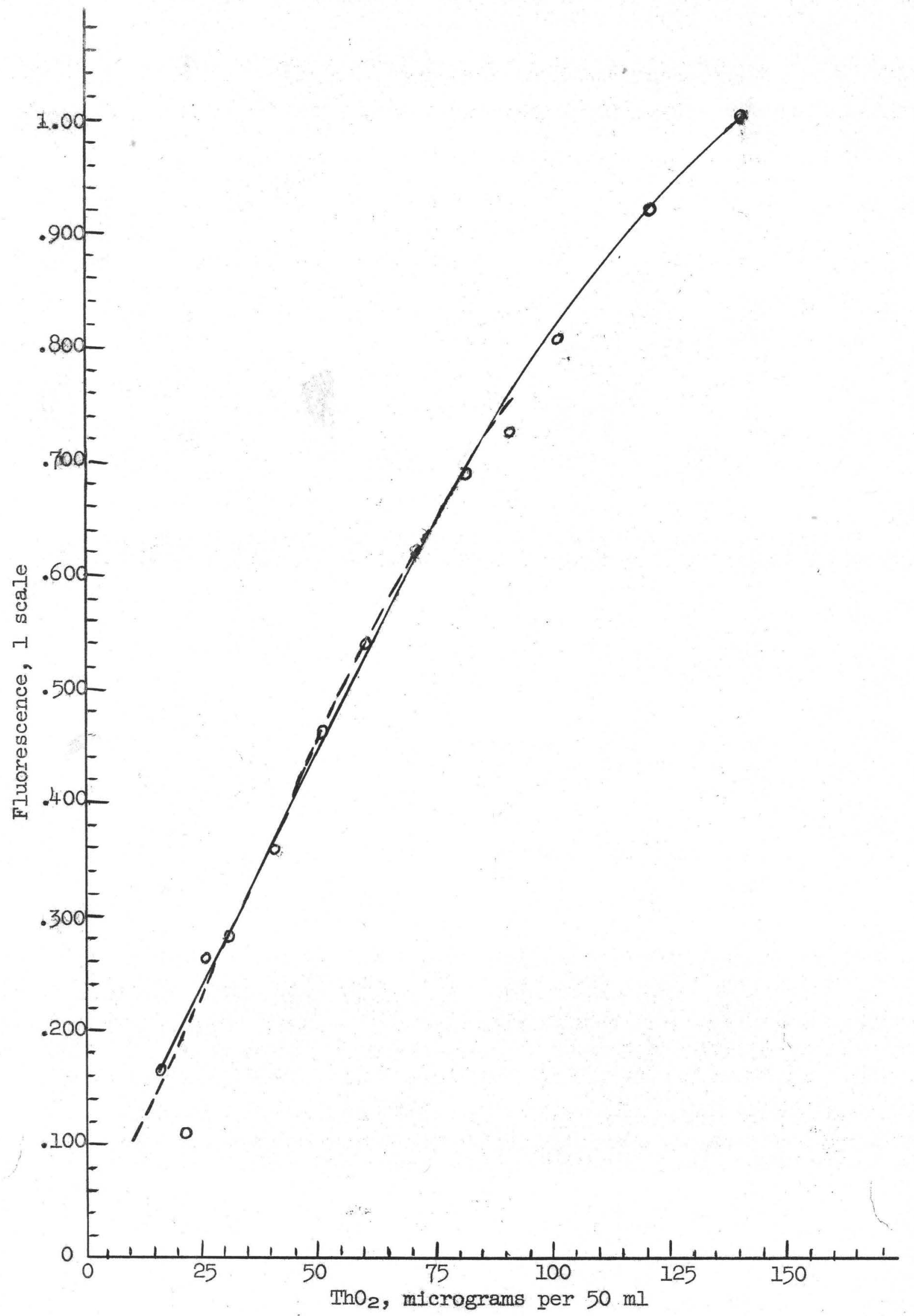




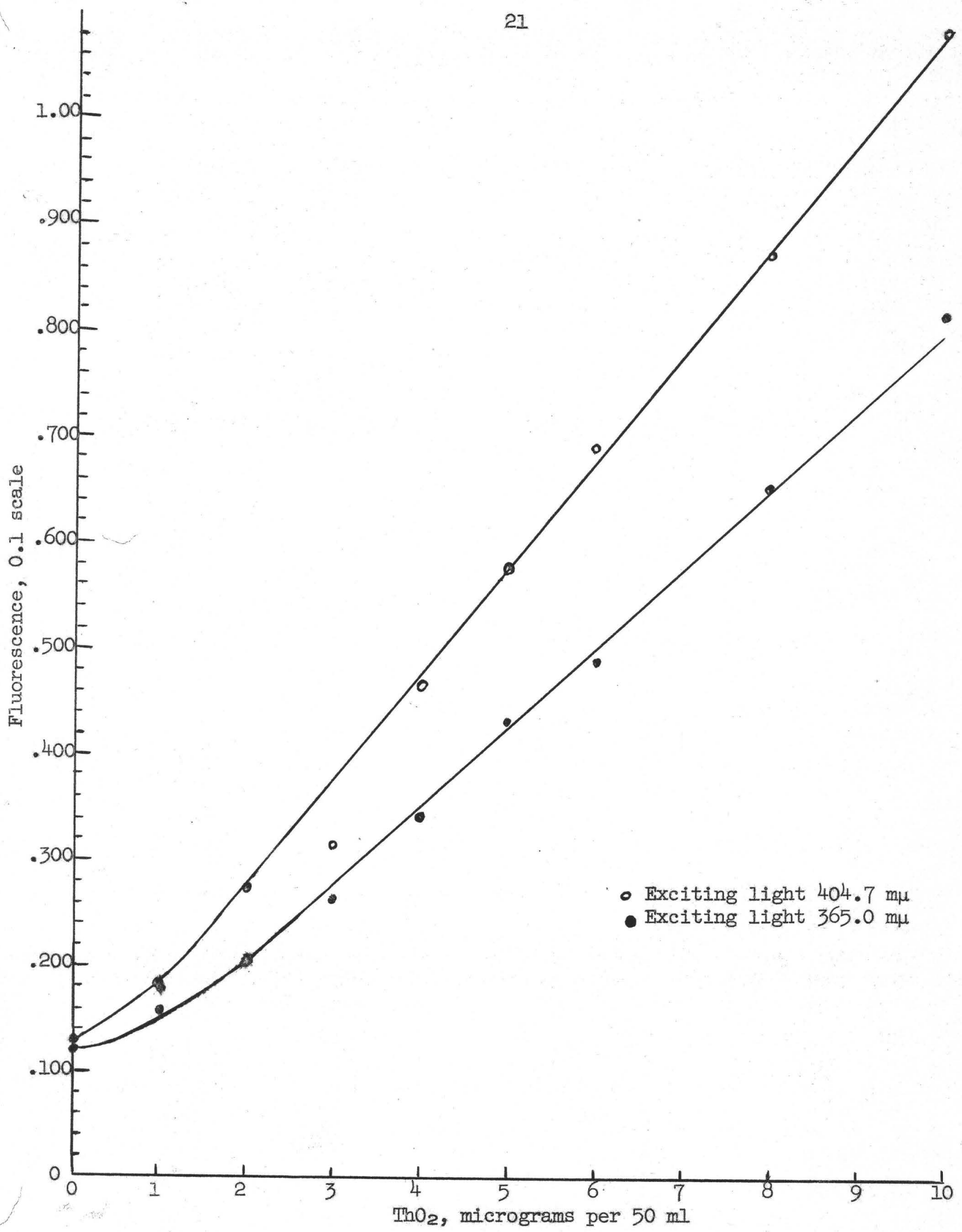

Figure 8.--Experimental standard curves. Total morin $=100$ micrograms per $50 \mathrm{ml}$; alcohol $=2 \mathrm{ml}$ per $50 \mathrm{ml}$. 
Comparison of fluorimetric and spectrophotometric methods

A sensitivity of 0.5 microgram of $\mathrm{ThO}_{2}$ is slightly less than but comparable to that of the spectrophotometric method (2). Potentially, however, the sensitivities of the two methods are far different provided. the random errors can be eliminated from the fluorimetric method. As indicated above, the limit of detection of the fluorimetric method is as Iow as 0.044 microgram. Although the sensitivity of the spectrophotometric method can be improved only by such limited means as increasing the light path beyond $5 \mathrm{~cm}$, the sensitivity of the fluorimetric method could be increased greatly by several different means.

Increased fluorescence could be produced by using higher concentrations of alcohol and by lincreasing the intensity of the exciting light by moving the lamp closer to the sample. Additional sensitivity could be obtained instrumentally by increasing the amplification of the photocurrent. However, unless the precision were improved these expedients would result in increasing the random errors proportionately with no resultant net gain. Hence, at present, the spectrophotometric method is more advantageous for quantitative analysis.

\section{Effect of other ions}

Zirconium, aluminum, and ferric ions that are serious interferences in the spectrophatometric method, and calcium and lanthanum, which might be useful as carriers in separations of thorium from other ions, were tested for their fluorescent reactions with morin. In all of these tests, the solutions contained $2 \mathrm{ml}$ of alcohol and the ion was tested both alone and in the presence of 5 micrograms of $\mathrm{ThO}_{2}$ per $50 \mathrm{ml}$ of solution. Zirconium 
and aluminum were tested with exciting wavelengths of both $404.7 \mathrm{mu}$ and $365.0 \mathrm{~m} \mu$, and as the effects of these ions were the same at both wavelengths, ferric, calcium, and lanthanum ions were tested at $404.7 \mathrm{m \mu}$ only. Both zirconium and aluminum fluoresce with morin and would cause a positive error in analytical work. Ferric ions seriously quench the fluorescence of thorium. and would cause a negative error. Small amounts of calcium and lanthanum produce little or no effect, and apparently small amounts of either could be used as a carrier in separations of thorium from other ions.

A summary of these tests is given in table 1.

Table 1.--Summary of effects of other ions.

\begin{tabular}{|c|c|c|c|}
\hline Ion & $\begin{array}{l}\text { Type of } \\
\text { interference }\end{array}$ & $\begin{array}{l}\text { Sensitivity of } \\
\text { fluorescence of } \\
\text { interfering ion }\end{array}$ & $\begin{array}{l}\text { Amount of interfering } \\
\text { substance which causes } 10 \% \\
\text { error in amount of } \mathrm{ThO}_{2} \text { found }\end{array}$ \\
\hline $\mathrm{Zr}^{+4}$ & $\begin{array}{l}\text { Forms complex } \\
\text { which fluoresces }\end{array}$ & $\begin{array}{l}\mathrm{ZrO}_{2} \text { and } \mathrm{ThO}_{2} \\
\text { approximately the } \\
\text { same }\end{array}$ & $\begin{array}{l}\mathrm{ZrO}_{2}=10 \% \text { of the amount of } \\
\mathrm{ThO}_{2} \text { present }\end{array}$ \\
\hline $\mathrm{AI}^{+3}$ & $\begin{array}{l}\text { Forms complex } \\
\text { which fluoresces }\end{array}$ & $\begin{array}{l}\mathrm{Al}_{2} \mathrm{O}_{3} \text { about } 1 / 8 \text { as } \\
\text { sensitive as } \mathrm{ThO}_{2}\end{array}$ & $\begin{array}{l}\mathrm{Al}_{2} \mathrm{O}_{3}=\text { amount of } \mathrm{ThO}_{2} \\
\text { present }\end{array}$ \\
\hline $\mathrm{Fe}^{+3}$ & $\begin{array}{l}\text { Quenches the } \\
\text { thorium-morin } \\
\text { fluorescence }\end{array}$ & -- & $\begin{array}{l}15-20 \text { micrograms } \mathrm{Fe}_{2} \mathrm{O}_{3} \\
\text { per } 50 \mathrm{ml}\end{array}$ \\
\hline $\mathrm{Ca}^{+2}$ & $\begin{array}{l}\text { Quenches the } \\
\text { thorium-morin } \\
\text { fluorescence }\end{array}$ & -- & $2 \mathrm{mg} \mathrm{CaO}$ per $50 \mathrm{ml}$ \\
\hline $\mathrm{La}^{+3}$ & $\begin{array}{l}\text { Quenches the } \\
\text { thorium-morin } \\
\text { fluorescence }\end{array}$ & -- & $5 \mathrm{mg} \mathrm{La}_{2} \mathrm{O}_{3}$ per $50 \mathrm{ml}$ \\
\hline
\end{tabular}


BASIC THEORY OF FLUORESCENCE? APPLICATION TO THORIUM-MORIN SYSTEM

The theoretical factors affecting the fluorescence of the thorium-morin system are more complicated than those of the spectrophotometric system. To understand the fluorescent system better, it was studied in the following manner:

A mathematical analysis of the relationship between light absorption. and fluorescence was made and a general equation derived for the fluorescence produced in a three-component system assuming that all three components absorb exciting light, all three fluoresce, and all three absorb the fluorescence. This general equation reduces to simpler forms when applied to less complicated systems where many of the terms of the general equation become zero. A specific expression that applies to the thorium-morin system was obtained from one of these simpler equations by addition of a quenching factor and substitution of the proper constants. The validity of this expression is shown by the close agreement between calculated and experimental standard curves.

\section{Derivation of the general equation}

Consider a cell containing a solution with the light source above the solution and the phototube below the cell.

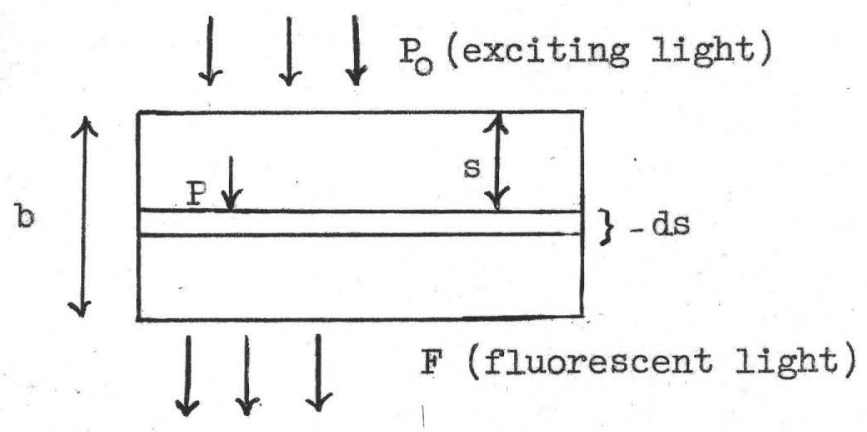


Assume that the exciting light is monochromatic and that the absorption follows Beer's law:

$$
P=P_{0}\left(e^{-k c s}\right)
$$

where $P$ is light intensity,

c is concentration,

$\mathrm{k}$ is absorptivity, and

$s$ is distance from the surface of the solution to the fluorescing substance in differential layer ds.

Fluorescence of metal ion

If the solution contains a metal ion, the reagent, and the complex, and if all three absorb exciting light, then the intensity of the exciting light $(P)$ entering the layer ds is expressed:

$$
P=P_{0} e^{-\left(k_{1} c_{I}+k_{2} c_{2}+k_{3} c_{3}\right) s}
$$

where the subscript I refers to the metal ion, subscript 2 refers to the reagent, and subscript 3 refers to the complex. Then, the light intensity absorbed in the differential layer ds is given by the expression

$$
d P=-P_{0}\left(k_{1} c_{1}+k_{2} c_{2}+k_{3} c_{3}\right) e^{-\left(k_{1} c_{1}+k_{2} c_{2}+k_{3} c_{3}\right) s} d s
$$

Let $K_{M}$ = factor for conversion of the absorbed exciting light to fluorescent light when the metal ion is the fluorescent component.

$V=$ fraction of unabsorbed fluorescent light which impinges on the phototube, the geometrical factor. (If the distance from the solution cell to the phototube is much larger than the distance $b$, then $V$ will be substantially constant for all values of $\mathrm{s}$ or all positions of ds.)

$\mathrm{k}_{4}=$ absorptivity of the metal ion for the fluorescent light emitted by the metal ion. 
$k_{5}=$ absorptivity of the reagent for the fluorescent light emitted. by the metal ion.

$\mathrm{k}_{0}=$ absorptivity of the complex for the fluorescent light emitted. by the metal ion.

(As the wavelengths of the fluorescent light emitted would probably extend over a range of values, the $k_{4}, k_{5}$, and $k_{6}$ are understood to be average values for the wavelength band.)

The fluorescent light, $\mathrm{dF}_{\mathrm{M}_{0}}$, arising from the metal ion in the element ds is proportional to the fraction of light absorbed by the metal ion in the element ds:

$$
d F_{M_{0}}=K_{M}\left[\frac{k_{1} c_{1}}{k_{1} c_{1}+k_{2} c_{2}+k_{3} c_{3}}\right][d P]
$$

The unabsorbed fraction of this fluorescence which impinges on the phototube is expressed by the equation:

$$
\begin{aligned}
& d F_{M}=K_{1} P_{0}\left(k_{1} c_{1}\right)\left[e^{-\left(k_{1} c_{1}+k_{2} c_{2}+k_{3} c_{3}\right) s}\right] \cdot\left[e^{-\left(k_{4} c_{1}+k_{5} c_{2}+k_{6} c_{3}\right)(b-s)}\right] d s \\
& \text { where } \mathrm{K}_{1}=\mathrm{VK}_{\mathrm{M}}
\end{aligned}
$$

$\therefore d F_{M}=k_{1} P_{0}\left(k_{1} c_{1}\right)\left[e^{-\left(k_{4} c_{1}+k_{5} c_{2}+k_{6} c_{3}\right) b}\right] \cdot\left[e^{-\left[\left(k_{1}-k_{4}\right) c_{1}+\left(k_{2}-k_{5}\right) c_{2}+\left(k_{3}-k_{6}\right) c_{3}\right] s}\right] d s$

The fluorescent light (due to the metal ion in the entire solution) which impinges on the phototube is obtained by a summation of the differential elements ds between the limits of zero and $\mathrm{b}$ and results in the integrated expression $F_{M}=\frac{K_{1} P_{0}\left(k_{1} c_{1}\right)}{\left(k_{1}-k_{4}\right) c_{1}+\left(k_{2}-k_{5}\right) c_{2}+\left(k_{3}-k_{6}\right) c_{3}}\left[e^{-\left(k_{4} c_{1}+k_{5} c_{2}+k_{6} c_{3}\right) b}-e^{-\left(k_{1} c_{1}+k_{2} c_{2}+k_{3} c_{3}\right) b}\right]$ 


\section{Fluorescence of reagent}

By a similar procedure, an expression can be obtained for the fluorescent light arising from the reagent in the solution:

Let $K_{R}=$ conversion coefficient for exciting light to fluorescent light when the reagent is the fluorescent component.

$$
\mathrm{V} \text { = fraction of unabsorbed fluorescent light that impinges on }
$$

the phototube.

$\mathrm{k}_{7}=$ absorptivity of the metal ion for the fluorescent light emitted by the reagent.

$\mathrm{k}_{8}=$ absorptivity of the reagent for the fluorescent light emitted by the reagent.

$\mathrm{k}_{9}=$ absorptivity of the complex for the fluorescent light emitted by the reagent.

Again, the absorptivities are assumed to be average values for the waveband of fluorescence. Accordingly, the expression for the fluorescence due to the reagent in the solution which impinges on the phototube is $F_{R}=\frac{k_{2} P_{0}\left(k_{2} c_{2}\right)}{\left(k_{1}-k_{7}\right) c_{1}+\left(k_{2}-k_{8}\right) c_{2}+\left(k_{3}-k_{9}\right) c_{3}}\left[e^{-\left(k_{7} c_{1}+k_{8} c_{2}+k_{9} c_{3}\right) b}-e^{-\left(k_{1} c_{1}+k_{2} c_{2}+k_{3} c_{3}\right) b}\right]$ (.....(4)

where $\quad \mathrm{K}_{2}=\mathrm{VK}_{\mathrm{R}}$

Fluorescence of complex

Let $\mathrm{K}_{\mathrm{C}}=$ conversion factor for exciting light to fluorescent light when the complex is the fluorescent component. $\mathrm{V}=$ fraction of unabsorbed fluorescent light that impinges on the phototube. 
$\mathrm{k}_{10}=$ absorptivity of the metal ion for the fluorescent light emitted by the complex.

$\mathrm{k}_{11}=$ absorptivity of the reagent for the fluorescent light emitted by the complex.

$k_{12}=$ absorptivity of the complex for the fluorescent light emitted by the complex.

The absorptivities again are assumed to be average values for the waveband of the fluorescence.

Then the fluorescence, due to the complex in the solution, which impinges on the phototube is

$F_{C}=\frac{K_{3} P_{0}\left(k_{3} c_{3}\right)}{\left(k_{1}-k_{10}\right) c_{1}+\left(k_{2}-k_{11}\right) c_{2}+\left(k_{3}-k_{12}\right) c_{3}}\left[e^{-\left(k_{10} c_{1}+k_{11} c_{2}+k_{12} c_{3}\right) b}-e^{-\left(k_{1} c_{1}+k_{2} c_{2}+k_{3} c_{3}\right) b}\right]$

where $\mathrm{K}_{3}=\mathrm{VK}_{\mathrm{C}}$

Total fluorescence

In equations 3, 4, and 5, the exponential functions are expressed to the base e. In practical usage, however, the exponentials are usually expressed to the base 10 , and in this case, the absorptivities $\mathrm{k}_{\mathrm{n}}$ of equations 3,4 , and 5 become $0.434 \mathrm{k}_{\mathrm{n}}$. Moreover, to be more specific in terminology, when the concentrations $c_{1}, c_{2}$, and $c_{3}$ are expressed as weight per unit volume, the absorptivity $0.434 \mathrm{k}_{\mathrm{n}}$, is expressed as $a_{n}$ ( $\epsilon_{\mathrm{n}}$ when concentration is in terms of moles per liter). Thus, expressing the exponential functions to the base 10 and the concentrations in terms of weight per unit volume, the final equation for total fluorescence reaching 
the phototube becomes:

$$
\begin{aligned}
F= & F_{M}+F_{R}+F_{C} \\
= & \frac{K_{1} P_{0}\left(a_{1} c_{1}\right)\left[10^{-\left(a_{4} c_{1}+a_{5} c_{2}+a_{6} c_{3}\right) b}-10^{-\left(a_{1} c_{1}+a_{2} c_{2}+a_{3} c_{3}\right) b_{b}}\right]}{\left[\left(a_{1}-a_{4}\right) c_{1}+\left(a_{2}-a_{5}\right) c_{2}+\left(a_{3}-a_{6}\right) c_{3}\right]}+ \\
& \frac{K_{2} P_{0}\left(a_{2} c_{2}\right)\left[10^{-\left(a_{7} c_{1}+a_{8} c_{2}+a_{9} c_{3}\right) b}-10^{-\left(a_{1} c_{1}+a_{2} c_{2}+a_{3} c_{3}\right) b}\right]}{\left[\left(a_{1}-a_{7}\right) c_{1}+\left(a_{2}-a_{8}\right) c_{2}+\left(a_{3}-a_{9}\right) c_{3}\right]}+ \\
& \frac{K_{3} P_{0}\left(a_{3} c_{3}\right)\left[10^{-\left(a_{10} c_{1}+a_{11} c_{2}+a_{12} c_{3}\right) b}-10^{-\left(a_{1} c_{1}+a_{2} c_{2}+a_{3} c_{3}\right) b}\right]}{\left[\left(a_{1}-a_{10}\right) c_{1}+\left(a_{2}-a_{11}\right) c_{2}+\left(a_{3}-a_{12}\right) c_{3}\right]} \ldots .
\end{aligned}
$$

Application to simplified systems

Equation 6 represents the generalized case where all three of the components in the solution absorb the exciting light, all three fluoresce, and all three absorb the fluorescent light. In actual practice most systems will be much'simpler than this, and the equation will accordingly be much simplified. Thus, when the complex alone absorbs exciting light and fluoresces, exciting light is not absorbed by the other two components, and fluorescent light is not absorbed by any of the three components, the equation reduces to the form

$$
F=K_{3} P_{0}\left(1-10^{-a_{3} c_{3} b}\right)
$$

(hereafter referred to as System I). This is the form of the equation usually found in the literature $(1,5,6)$.

When the complex and reagent both absorb exciting light, but the complex alone fluoresces, and fluorescent light is not absorbed by any of the three components, the theoretical equation becomes

$$
F=\frac{K_{3} P_{0}\left(a_{3} c_{3}\right)}{\left(a_{2} c_{2}+a_{3} c_{3}\right)}\left[1-10^{-\left(a_{2} c_{2}+a_{3} c_{3}\right) b_{1}}\right]
$$


(hereafter referred to as System II). Braunsberg and Osborn (1) have derited an equation, similar to this, to show the effect on fluorescence when the exciting light is absorbed by an impurity in the solution.

When the complex and metal ion both absorb exciting light, but only the complex fluoresces, and the fluorescent light is absorbed by the reagent, the equation becomes

$$
F=\frac{K_{3} P_{0}\left(a_{3} c_{3}\right)}{a_{1} c_{1}-a_{11} c_{2}+a_{3} c_{3}}\left[10^{-\left(a_{11} c_{2} b\right)}-10^{-\left(a_{1} c_{1}+a_{3} c_{3}\right) b}\right]
$$

Other systems can be postulated and analogous equations can be derived.

The derived equations express the fluorescence theoretically possible in solutions of fluorescent substances. However, if fluorescence quenching should occur in the solutions, then the derived mathematical expressions would be mitiplied by an extra term, which would express the fraction of maximum fluorescence that remained unquenched.

\section{Study of the fluorescence of the thorium-morin system}

In the process of applying the general equation (no.6) to a study of the thorium-morin system, it was necessary to consider each of the following variables: the concentrations of excess thorium, of complex, of excess morin, and of alcohol, and also the wavelength of exciting light.

In these studies the concentrations of each of the reactants and of the complex were varied individually to determine how each affects the fluorescence. Also, in many of these tests two different concentrations of alcohol, 2 and $1.2 \mathrm{ml}$, and two different wavelengths for the exciting light were used to study the effect on the fluorescence when it is produced under varying conditions of light absorption and also to determine whether $\mathrm{K}$, 
the factor for conversion of exciting energy to fluorescence, varies with alcohol concentration or wavelength of exciting light.

The absorbance data presented in figure 1 were considered in choosing the wavelengths to be used in the excitation of the fluorescence. At $410 \mathrm{m \mu}$ the absorbance of the complex is at its peak (curve B). Furthermore, the difference between the absorptivity of complex and the absorptivity of morin is at a maximum at $410 \mathrm{m \mu}$; as a consequence, interference resulting from light absorption by uncombined morin should be at a minimum at this wavelength. By analogous reasoning, at $350 \mathrm{m \mu}$ interference resulting from light absorption by the uncombined morin should be at a maximum. Thus, from the standpoint of light absorption only, $410 \mathrm{m \mu}$ should be the most advantageous exciting wavelength and $350 \mathrm{m \mu}$ the least advantageous.

These two wavelengths are quite close to the wavelengths of light emitted by the high-pressure mercury lamp--one of the most generally used. sources of ultraviolet light. This mercury lamp gives intense radiation at both $404.7 \mathrm{~m} \mu$ and $365.0 \mathrm{~m} \mu$, and light at each of these wavelengths can be isolated by filters. Accordingly, both the $404.7 \mathrm{m \mu}$ and $365.0 \mathrm{m \mu}$ radiations of the mercury lamp were used as exciting wavelengths in this work.

$$
\text { Effect of the concentration of excess thorium. }
$$

To test the effect of excess thorium on the fluorescence, a series of solutions were prepared in which the thorium concentration was increased to a point of great excess over that of the morin. In figure 9 the fluorescence of these solutions is shown as a function of the thorium concentration.

It has been shown (2) that 600 micrograms of morin are more than 98 percent reacted to form complex when as little as $7.5 \mathrm{mg}$ of $\mathrm{ThO}_{2}$ are present in $50 \mathrm{ml}$ of solution. The horizontal portion of the fluorescence 


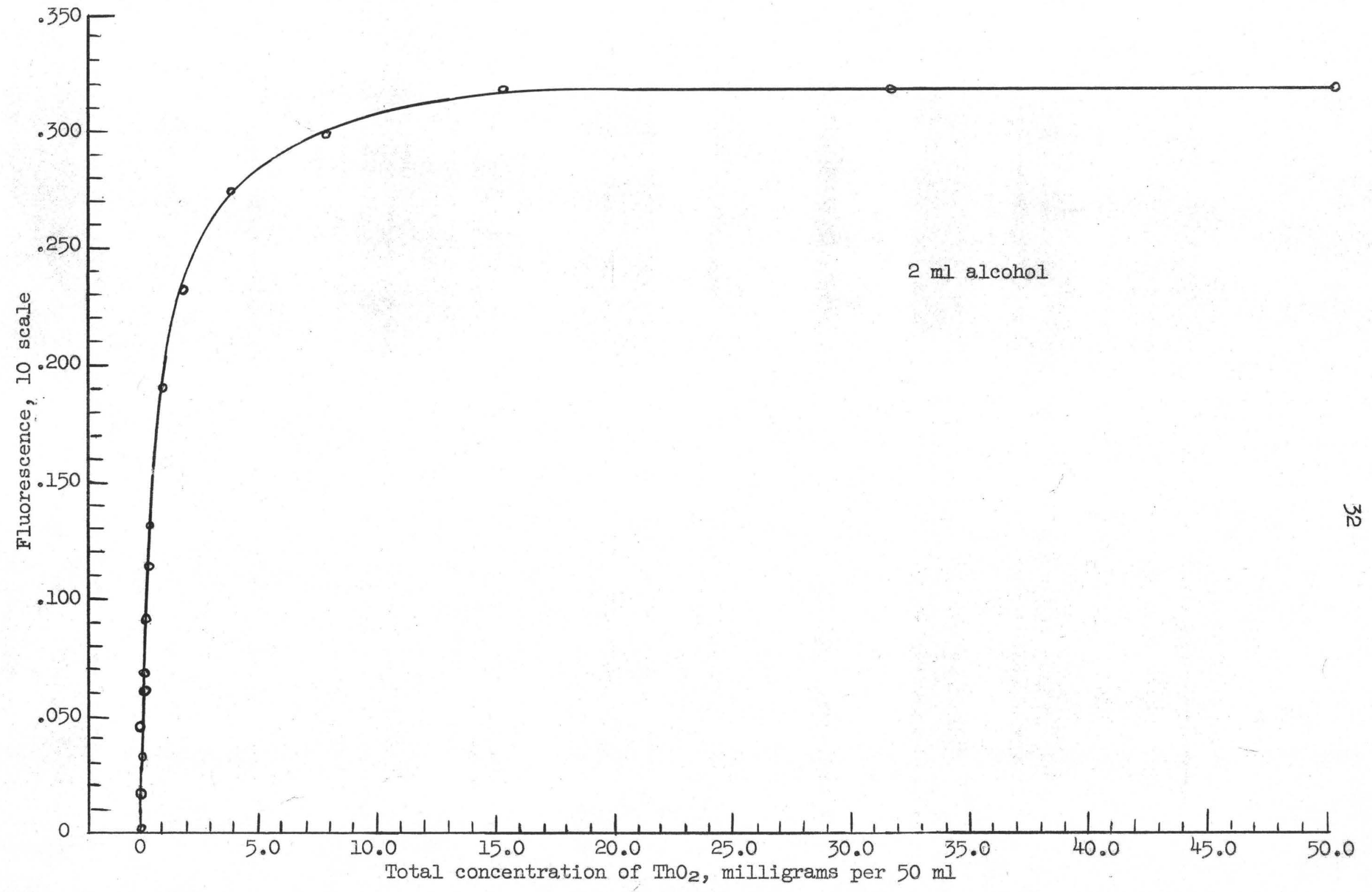

Figure 9.--Effect on fluorescence of adding increasing amounts of thorium to a constant amount of morin (600 micrograms per $50 \mathrm{ml}$; a.lcohol $2 \mathrm{ml}$; $\mathrm{P}_{\mathrm{O}}(404.7 \mathrm{m \mu})$. 
curve (fig. 9) is representative, therefore, of solutions that are mixtures of a constant amount of complex with varying amounts of excess thorium, and It shows that amounts of thorium as large as $50 \mathrm{mg} \mathrm{ThO}_{2}$ interfere in no discernible way with the fluorescence of the complex, as any quenching or absorption of either the exciting light or fluorescent light by the thorium would result in decreasing fluorescence as the thorium content increased. and any enhancement of fluorescence due to increased thorium concentration would cause the curve to rise. Thus, insofar as the fluorescence is concerned, solutions containing a mixture of the complex and a large excess of thorium can be considered as solutions of the pure complex alone. In this study $50 \mathrm{mg}$ of $\mathrm{ThO}_{2}$ were always used in the preparation of solutions of the so-called pure complex to insure that all of the morin would be completely converted to the form of complex.

Effect of the concentration of the complex

To determine the effect of the concentration of the complex on the fluorescence two series of solutions were prepared in which amounts of morin ranging from 0 to 4000 micrograms were converted completely to the complex by a large excess of thorium ( $50 \mathrm{mg} \mathrm{ThO}_{2}$ per $\mathrm{ml}$ ). In one series of solutions the alcohol content was $2 \mathrm{ml}$, whereas in the other series it was $12 \mathrm{ml}$.

The fluorescences of these solutions were determined using exciting lights having wavelengths of $404.7 \mathrm{~m} \mu$ and $365.0 \mathrm{m \mu}$ and a light path through the solutions of $3.241 \mathrm{~cm}$. The absorbances of these solutions at these wavelengths were calculated from data obtained with the Beckman spectrophotometer. As each of these solutions contained complex only plus a large 
amount of excess thorium, the complex was the only component of the solutions that absorbed the exciting light or emitted fluorescence and the system was similar to that described under Derivation as System I. Thus, the fluorescence produced in these solutions should obey equation 7 , $F=K_{3} P_{0}\left(1-10^{-A}\right)$, where $A=$ absorbance $=a_{3} c_{3} b$. Accordingly the fluorescence was plotted as a function of $\left(1-10^{-A}\right)$ which is equivalent to the fraction of exciting light absorbed by the complex. Curves A and B, figure 10, are representative of the solutions that contained 12 and $2 \mathrm{ml}$ of alcohol, respectively, when the exciting light had a wavelength of $404.7 \mathrm{m \mu}$. The curves obtained with an exciting light of wavelength $365.0 \mathrm{m \mu}$ are not presented because they are similar to those of figure 10.

The curves in figure 10 show that, within the limits of experimental error, the fluorescence increases linearly with the fraction of exciting light absorbed, (1-10 $\left.{ }^{-\mathrm{A}}\right)$; thus, in this region of linearity the conversion factor $K\left(K_{3}\right.$ of equation 7$)$ is a constant, and the fluorescence of the complex obeys the basic equation.

The slopes of the curves in figure 10 are equivalent to $\mathrm{KP}$ of the equation, and the empirical values for $\mathrm{KP}_{\mathrm{O}}$ calculated from the curves are given in table 2. The values obtained with exciting light of $365.0 \mathrm{~m} \mu$ are included also.

Table 2.--Empirical values for $\mathrm{KP}$ (for fluorescence readings on 10 scale).

Wavelength of exciting light (mu)
Empirical values for $\mathrm{KP}_{\mathrm{O}}$

$2 \mathrm{ml}$ of alcohol
$12 \mathrm{ml}$ of alcohol

$\begin{array}{lll}404.7 & 0.317 & 0.514 \\ 365.0 & 0.746 & 1.125\end{array}$




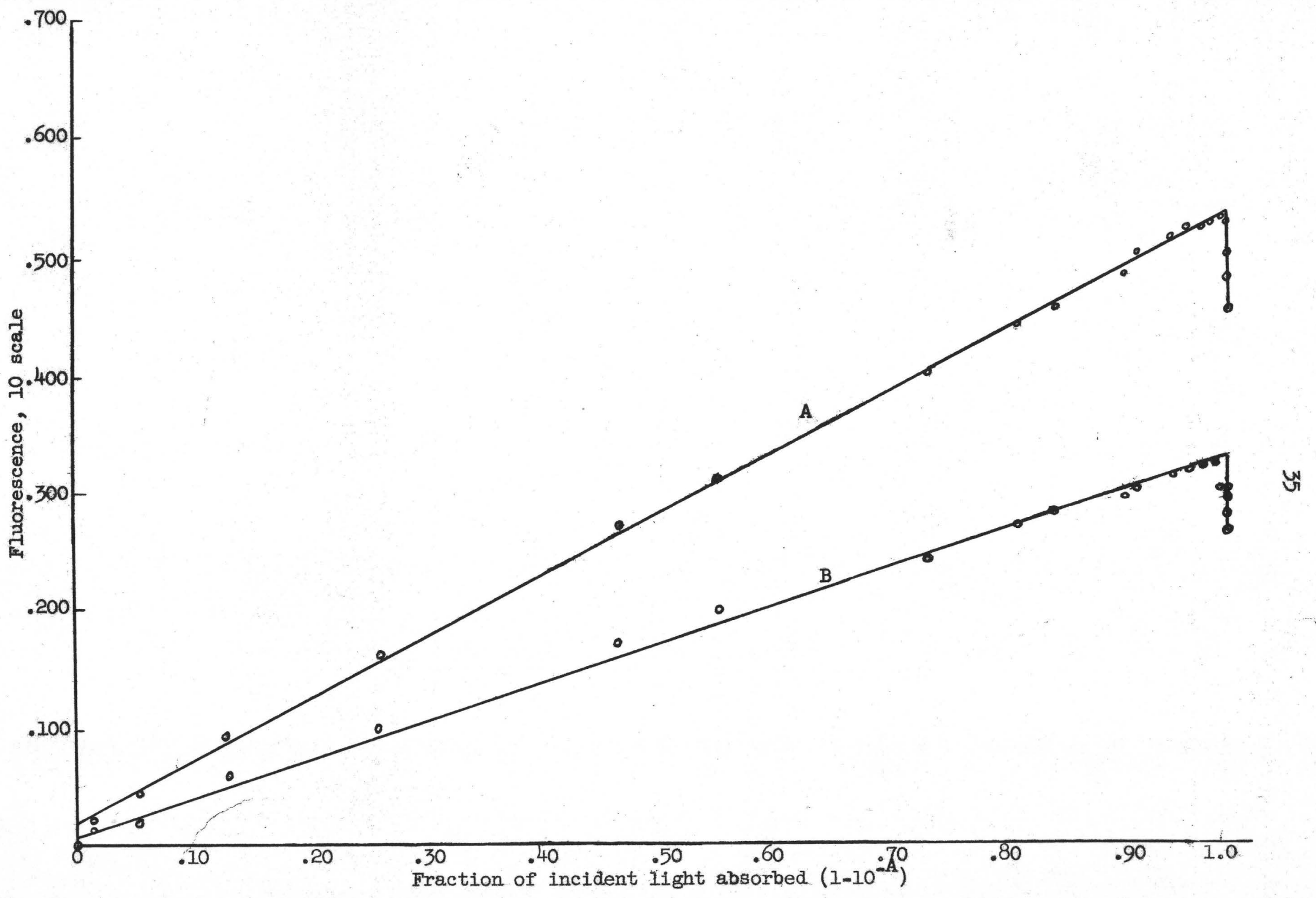

Figure 10.-Fluorescence of the complex as a function of the fraction of exciting light absorbed. Curve $\mathrm{A}, 12 \mathrm{ml}$ of alcohol per $50 \mathrm{ml}$; curve $\mathrm{B}, 2 \mathrm{ml}$ of alcohol per $50 \mathrm{ml}$; $\mathrm{P}_{\mathrm{O}}(404.7 \mathrm{m \mu})$. For each curve the concentration of the complex varied from 0 to 4934.4 micrograms per $50 \mathrm{ml}$ of solution. 
As table 2 shows, the value of $K_{0}$ is affected by alcohol content, but as $P_{0}$ is constant for each exciting wavelength used, the change in KP for each wavelength reflects a change in the factor $\mathrm{K}$ only. Thus, when the alcohol was increased from 2 to $12 \mathrm{ml}$ and the exciting light had a wavelength of $404.7 \mathrm{m \mu}, \mathrm{K}$ was increased by 62 percent; when the exciting light had a wavelength of $365.0 \mathrm{m \mu}$, $\mathrm{K}$ was increased by 51 percent.

The data in table 2 can also be used to obtain a rough comparison of $K$ at the two different wavelengths. The ratio of $\mathrm{KP}_{0}(404.7 \mathrm{mu})$ to $\mathrm{KP}_{\circ}(365.0 \mathrm{mu})$ for each concentration of alcohol is roughly 1 to 2. But the ratio of $P_{0}(404.7 \mathrm{m \mu})$ to $P_{0}(365.0 \mathrm{m \mu})$ is about 1 to 4 for the particular Iight source used.

When this difference in $P_{0}$ is considered, it becomes evident that $\mathrm{K}(404.7 \mathrm{mu})$ is about twice as large as $\mathrm{K}(365.0 \mathrm{m \mu})$ 。

Thus, not only $\left(1-10^{-A}\right)$, the fraction of $P_{0}$ that is absorbed by the complex, but $K$ also is greater when the exciting wavelength 404.7 mu is used rather than $365.0 \mathrm{m \mu}$. Accordingly, for light sources of equal energy at both wavelength, sensitivity will be considerably greater when the exciting wavelength is $404.7 \mathrm{mu}$ rather than $365.0 \mathrm{mu}$.

Returning to figure 10 it will be noted that a sharp break occurs in each curve when the fraction of light absorbed, $\left(1-10^{-\mathrm{A}}\right)$, equals nearly one, and any further increases in light absorption that result from increasing the concentration of complex are too small to result in a measurable increase in fluorescence, As a consequence the curves should terminate at this point of maximum fluorescence, which is equal to $\mathrm{KP}_{\mathrm{O}}$. However, at this point the curves in figure 10 break sharply and drop vertically, showing 
that increases in the concentration of the complex actually resulted in a slight decrease in the fluorescence.

A 15 percent decrease in fluorescence occurred when the concentration of the complex was increased from about 500 to nearly 5000 micrograms. Once maximum fluorescence is reached, increasing the concentration of complex results in the fluorescence becoming concentrated in an increasingly thinner layer at the surface of the solution thus increasing the distance between fluorescent region and the phototube. The fluorimeter was designed. to minimize the consequences of changes in the distance between fluorescence and phototube but the effect could not be entirely overcome; as a conse quence fluorescence readings in the high concentration range are Iower than the maximum value.

Taking this effect into account, the experimental curves over their entire range have the shape that would be expected from the basic equation with no evidence of significant self-quenching or enhancement of the fluorescence or changes in the value of $K$.

Effect of the concentration of uncombined morin.

To determine the effect of uncombined morin on the fluorescence of the complex, two series of solutions were prepared. In one series, each solution contained 50.3 micrograms of $\mathrm{ThO}_{2}, 12 \mathrm{ml}$ alcohol, and amounts of morin which ranged from 0 to 4000 micrograms per $50 \mathrm{ml}$ of solution; in the second series, each solution contained 50.3 micrograms of $\mathrm{ThO}_{2}$, only $2 \mathrm{ml}$ of alcohol, and amounts of morin which ranged from 0 to 1200 micrograms per $50 \mathrm{ml}$ of solution. Again the fluorescence intensity and the absorbance were measured using exciting light having wavelengths of 404.7 and $365.0 \mathrm{mu}$ for each set of measurements. 
The fluorescence readings were then plotted as a function of the total morin added. Curves A and B, figure 4, are representative of the solutions which contained $12 \mathrm{ml}$ of alcohol when the exciting wavelengths were $404.7 \mathrm{m \mu}$. and $365.0 \mathrm{m \mu}$, respectively; and curves A and B, figure 5, are representative of the solutions which contained $2 \mathrm{ml}$ of alcohol, when the exciting wavelengths were $404.7 \mathrm{m \mu}$ and. $365.0 \mathrm{m \mu}$, respectively.

If the uncombined morin, like the uncombined thorium, had no effect on the fluorescence, the curves in figures 4 and 5, like the curve in figure 9 should simply reflect the progress of complex formation. However, in the experimental curves, the fluorescence increases with the morin concentration. until a maximum point is reached, after which the curves break sharply and the fluorescence decreases as the amount of morin increases. The sharp break, which appears well before the point of complete reaction, and the subsequent decrease in the fluorescence are the result of two effects; absorption of exciting light by the nonfluorescent component of the solution (uncombined morin), and quenching of the fluorescence by uncombined morin.

An idea of the extent of this interference by uncombined morin can be obtained by considering the fluorescence of the solution which contained. 4000 micrograms of morin and $12 \mathrm{ml}$ of alcohol. The thorium in this solution was completely reacted to form 158.9 micrograms of complex, and this amount of complex in the absence of free morin should have given a fluorescence reading of 0.295 on the 10 scale of the fluorimeter. But the actual reading (curve A, fig. 4) was equivalent to 0.0092 on the 10 scale, which shows that the fluorescence had been reduced to less than 3 percent of its value by the presence of excess morin. 
It has been shown that the complex dissociates and that most of the thorium reacts to form complex only when relatively large amounts of uncombined morin are present (2). Thus, in addition to its absorption of exciting light, uncombined morin affects the fluorescence in two opposing ways. The fluorescence decreases with increase in morin as a result of quenching and increases with morin as a result of the law of mass action. Calculation of degree of reaction.--To make a more exact analysis of the effects of uncombined morin calculations were made to determine the components in the solutions of figures 4 and 5 . This was done using equation 8 of the spectrophotometric paper (2), which relates the absorbance of the solution to the amount of complex formed. The results of these calculations are shown in figure 11, where the fraction of total thorium that reacts to form complex in each solution is plotted as a function of the uncombined morin in the solution. The equation of this curve was derived as a function of the uncombined morin. For amounts of uncombined. morin up to 110 micrograms, the curve is represented by the expression

$$
R \text {, fraction of total } \mathrm{ThO}_{2} \text { reacted }=\frac{\mathrm{M} \cdot \mathrm{H}}{332-0.04(\mathrm{M} \cdot \mathrm{H})}
$$

where $\mathrm{M} \cdot \mathrm{H}=$ uncombined morin, micrograms $/ 50 \mathrm{ml}$. And for amounts of uncominined. morin from 110 to 200 micrograms, the expression is

$$
R \text {, fraction of total } \mathrm{ThO}_{2} \text { reacted }=\frac{\mathrm{M} \cdot \mathrm{H}}{0.906 \mathrm{M} \cdot \mathrm{H}+240}
$$

Determination of quenching by uncombined morin.--With the aid of the above mathematical expressions, it is possible to determine the relationship between the amount of uncombined morin present and the quenching of the fluorescence. Most of the solutions whose data are plotted in figure 11 
40

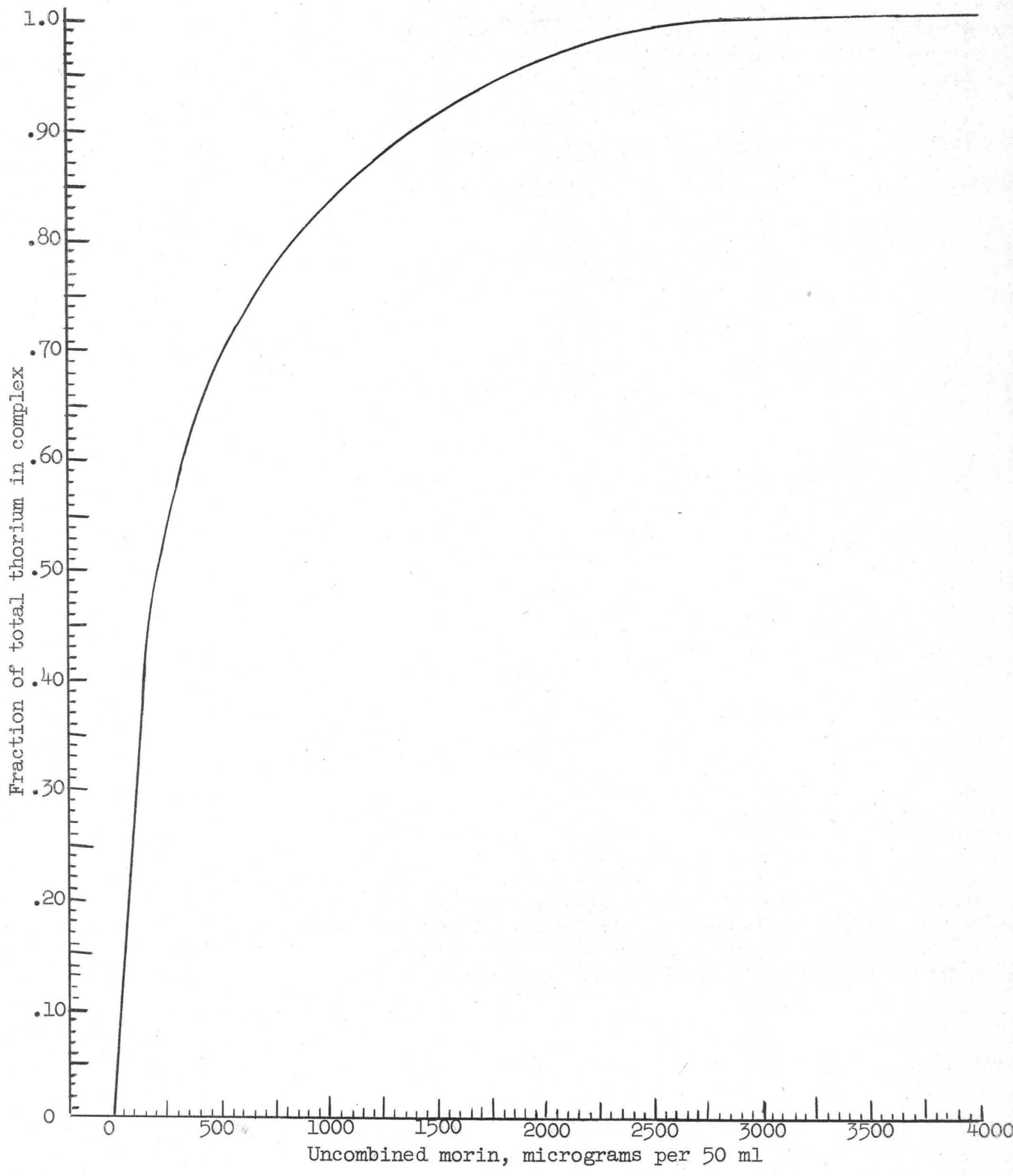

Figure 11.-Fraction of total thorium converted to complex as a function of uncombined morin in the solution. Thorium constant at 50.3 micrograms of $\mathrm{ThO}_{2}$ per $50 \mathrm{ml}$. 
represent examples of System II, (equation 8), because sizable amounts of uncombined morin are present as well as complex and both absorb significant amounts of exciting light. Accordingly, the total fluorescence that is theoretically possible in these solutions is represented by the following equation when the exciting wavelength is $404.7 \mathrm{m \mu}$ :

$$
\text { Total fluorescence }=\frac{K_{3} P_{0}\left(a_{3} C R\right)}{a_{2} M \cdot H+a_{3} C R} \quad\left[1-10^{-}\left(a_{2} M \cdot H+a_{3} C R\right) b\right]
$$

where $\mathrm{K}_{3} \mathrm{P}_{0}=3.17$ (for a total alcohol content of $2 \mathrm{ml}$ ) ( 1.0 scale) $=5.14$ (for a total alcohol content of $12 \mathrm{ml})(1.0$ scale) $a_{2}=\left(6.179 \times 10^{-5}\right)=$ absorbance of 1 microgram of morin $/ 50 \mathrm{ml}$, $1 \mathrm{~cm}$ light path $a_{3}=\left(9.404 \times 10^{-4}\right)=$ absorbance of 1 microgram of complex $/ 50 \mathrm{ml}$, $1 \mathrm{~cm}$ light path

$$
\begin{aligned}
\mathrm{M} \cdot \mathrm{H} & =\text { uncombined morin, micrograms } / 50 \mathrm{ml} \\
\mathrm{C} & =\text { maximum complex possible from } 50.3 \text { micrograms } \mathrm{ThO}_{2} \\
& =158.9 \text { micrograms }
\end{aligned}
$$

$R=$ fraction of total thorium reacted, represented either by equation 10 or 11. $\mathrm{b}=3.241 \mathrm{~cm}$,

Using this equation, calculations were made for the total theoretical fluorescence corresponding to the different levels of uncombined morin. Experimental values for the fluorescence of these solutions were obtained from the curves in figures 4 and 5 by reading the fluorescence for concentrations of total morin equivalent to the different levels of uncombined morin. Division of the experimental value by the theoretical value for each amount of uncombined morin gave the fraction of the total possible 
fluorescence that remained unquenched. These values for the unquenched. fluorescence, $U$, have been plotted in figure 12. Curve A, figure 12, represents those solutions containing a total alcohol content of $12 \mathrm{ml}$, and curve B represents those with a total alcohol content of $2 \mathrm{ml}$.

Equations for these curves were derived. For curve $\mathbb{A}$, the fraction of unquenched fluorescence as a function of $\mathrm{M} \cdot \mathrm{H}$, the uncombined morin, is expressed by the formula:

$$
U=0.864-\left[\frac{\mathrm{M} \cdot \mathrm{H}-50}{154.4+1.142 \mathrm{M} \cdot \mathrm{H}}\right]
$$

and for curve $B$, the expression is

$$
U=0.861-\left[\frac{\mathrm{M} \cdot \mathrm{H}-43.16}{6 I+1.115 \mathrm{M} \cdot \mathrm{H}}\right] \text {. }
$$

These expressions apply for values of $\mathrm{M} \cdot \mathrm{H}$ greater than about 50 micrograms; for smaller values of $\mathrm{M} \cdot \mathrm{H}$ the points defining the curves in figure 12 were erratic.

Calculation of optimum morin concentration.--As the quenching is a function of the uncombined morin only, the above expressions should apply for a,ll levels of $\mathrm{ThO}_{2}$ concentration and should be inserted in the general equation for fluorescence as a common multiplier. Thus, the equation of System II may now be expressed as it applies specifically to the thorium-morin fluorescent system when total alcohol content of the solutions is $2 \mathrm{ml}$. 


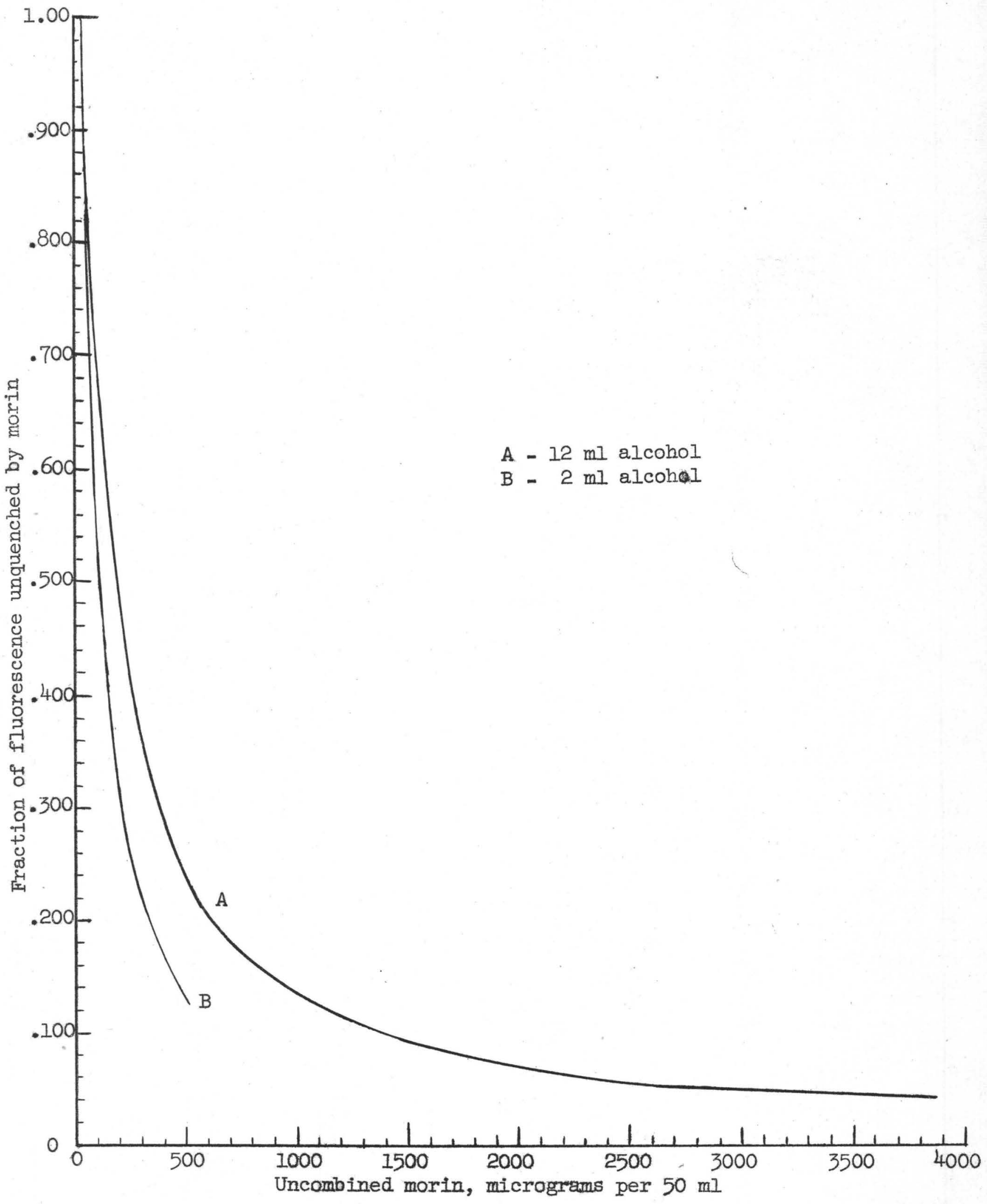

Figure 12.-Fraction of fluorescenee remaining wnquenched as a function of ... the uncombined morin. Thorium constant at 50.3 mierograms of $\mathrm{ThO}_{2}$ per $50 \mathrm{ml}$. Curve A, $12 \mathrm{ml}$ of alcohol; curve B, $2 \mathrm{ml}$ of alcohol; $P_{0}(404.7 \mathrm{m \mu})$. 


$$
F=\left[0.861-\frac{M \cdot H-43.16}{61+1.115 M \cdot H}\right] \frac{K_{3} P_{0}\left(a_{3} C R\right)}{a_{2} M \cdot H+a_{3} C R}\left[1-10^{-\left(a_{2} M \cdot H+a_{3} C R\right) b}\right.
$$

where $\mathrm{C}=$ maximum complex possible from the $\mathrm{ThO}_{2}$ present in micrograms per $50 \mathrm{ml}$ of solution

$\mathrm{R}$ = fraction of total $\mathrm{ThO}_{2}$ reacted to form complex

$\mathrm{CR}=$ complex present in solution in micrograms per $50 \mathrm{ml}$.

This equation is useful because the fluorescence of any solution can be calculated, provided the concentrations of complex and of uncombined morin are known. Such concentrations were calculated from experimental data for two series of solutions: the solutions of the one series containing a total of 50.3 micrograms $\mathrm{ThO}_{2}$ per $50 \mathrm{ml}$ and varying amounts of total morin; and the solutions of the other series containing a total of 15 micrograms $\mathrm{ThO}_{2}$ per $50 \mathrm{ml}$ and varying amounts of total morin.

Then, using equation 12, the fluorescences of these solutions were calculated. Curves in which the calculated fluorescences were plotted as a function of uncombined morin were similar to curve $A$ in figure 5 . Figure 13 shows the portions of the calculated curves, between 50 and 200 micrograms of uncombined morin, which include the peaks of the curves. The peaks of both these curves, and thus the region of greatest sensitivity, occur when the uncombined morin is near 100 micrograms; furthermore, the maximum variation in fluorescence is less than 5 percent when morin varies from 75 to 130 micrograms.

The almost constant fluorescence indicates that in this limited range the effect of increased complex formation resulting from increased morin concentration is almost exactly counterbalanced by the increased effects of 


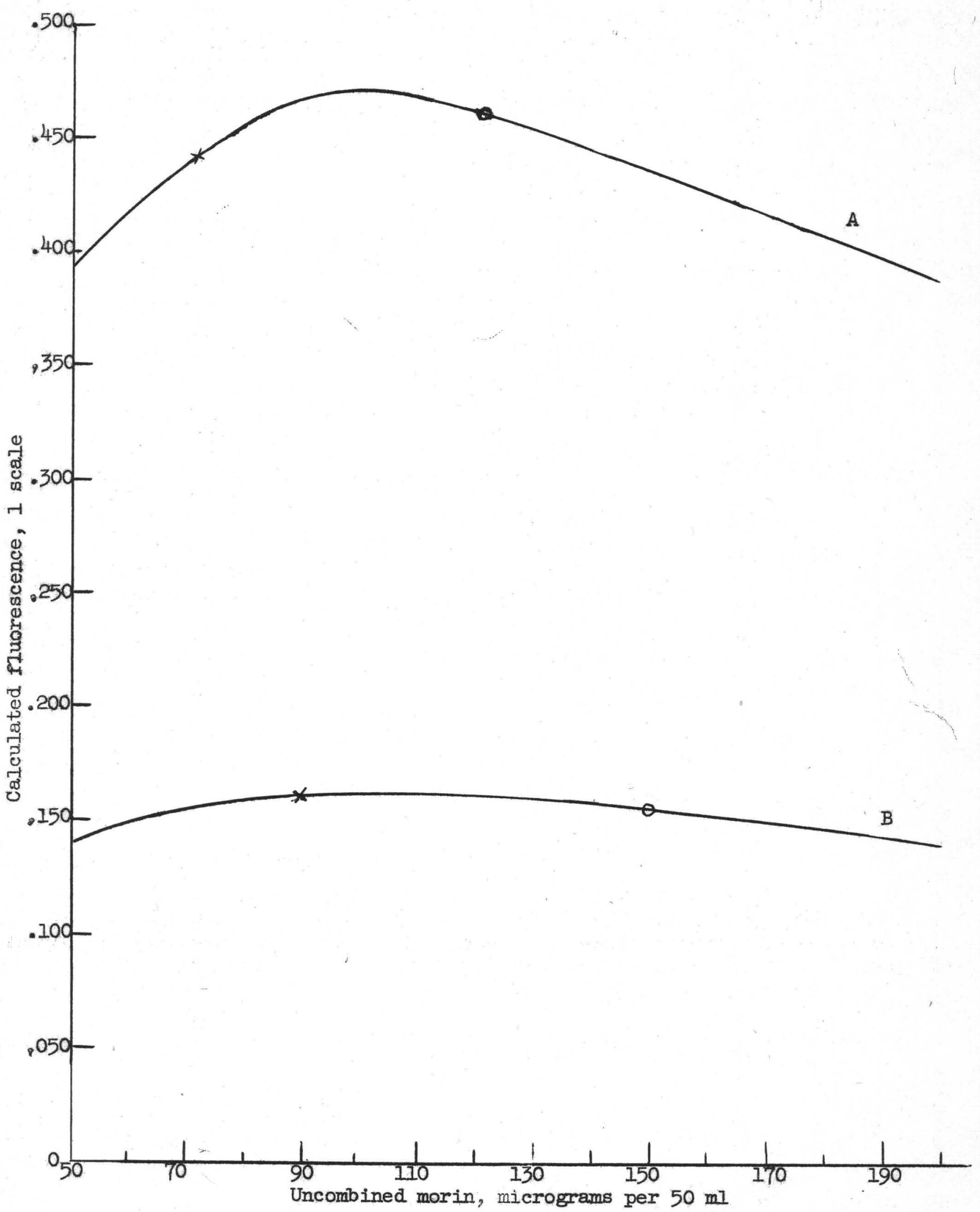

Figure 13.--Calculated fluorescence as a function of uncombined morin in the solutions. Curve A, total thorium 50.3 -micrograms of $\mathrm{ThO}_{2}$ per $50 \mathrm{ml}$; curve $\mathrm{B}$, total thoriur 15 micrograms of $\mathrm{ThO}_{2}$ per $50 \mathrm{ml} ; 2 \mathrm{ml}$ of alcohol; $\mathrm{P}_{\mathrm{O}}(404.7 \mathrm{m \mu})$. 
quenching and absorption of exciting light by morin.

This result is fortuitous for the construction of standard curves. If the total morin reagent added to the solutions results in amounts of uncombined morin between the limits of 75 and 150 micrograms per $50 \mathrm{ml}$, then close to maximum sensitivity and linearity for the standard curve are attained. A choice of 100 micrograms total morin content results in values for uncombined morin near the lower limit of this range (see crosses in figure 13) and a choice of 165 micrograms of total morin results in uncombined. morin values near the upper limit of the range (circles in figure 13 ).

\section{Calculation of standard curve}

Equation 12 was used to compute standard curves after the term $\mathrm{CR}$ (amount of complex formed.) was evaluated for thorium concentrations in the range of the standard curve. This evaluation is necessary because $R$, the fraction of total thorium reacted to form complex, was derived only for solutions having total thorium concentrations of 50.3 and. 15 micrograms of $\mathrm{ThO}_{2}$. CR was evaluated using the mass action law:

$$
\frac{(\mathrm{CR})\left(\mathrm{H}^{+}\right)^{2}}{\left(\mathrm{ThO}_{2}-\mathrm{CR}\right)(\mathrm{M} \cdot \mathrm{H}-2 \mathrm{CR})^{2}}=\mathrm{K}_{\mathrm{E}}
$$

where

$$
\begin{aligned}
(\mathrm{CR}) & =\text { complex formed, moles per liter } \\
(\mathrm{M} \cdot \mathrm{H}) & =\text { total morin, moles per liter } \\
(\mathrm{M} \cdot \mathrm{H}-\mathrm{CCR}) & =\text { uncombined morin, moles per liter } \\
\left(\mathrm{ThO}_{2}\right) & =\text { total thorium, moles per liter } \\
\left(\mathrm{ThO}_{2}-\mathrm{CR}\right) & =\text { uncombined thorium, moles per liter } \\
\mathrm{K}_{\mathrm{E}} & =\text { equilibrium constant. }
\end{aligned}
$$


$\mathrm{K}_{\mathrm{E}}$ had been determined previously (2); for thorium concentrations in the range of the standard curve the average values of $K_{\mathrm{E}}$ are $1.45 \times 10^{6}$ when total morin is 100 micrograms, and $0.95 \times 10^{6}$ when total morin is 165 micrograms.

The calculated standard curves are shown in figures 6 and 7 as dashed lines; they coincide very closely with the experimental curves. Both the region of linearity and slope predicted by the calculated curves are corroborated by the experimental curves. It is possible, thus, to use the derived mathematical expressions for fluorescence to calculate a family of curves that show, without actual experimentation, the characteristics of the standard curves to be expected for total morin concentrations that vary over a wide range.

\section{LITERATURE CITED}

(I) Braunsberg, H., and Osborn, S. B., Some general aspects of fluorimetric determinations: Anal. Chim. Acta, v, 6, p. 84-95, 1952.

(2) Fletcher, Mary H., and Milkey, Robert G., Spectrophotometric study of the thorium-morin mixed-color system: Anal. Chemistry, v. 28, p. 1402-1407, 1956.

(3) Gôto, Hidehiro, Fluorescence analysis VI. Fluorescent detection: Chem. Soc. Japan Jour., v. 59, p. 625-633, 1933.

(4) pto, Hidehiro, Fluorescence analysis VI. Fluorescence detection: Tohoku Imp. Univ. Sci. Repts., Ist ser., p. 287-303, 1940-41.

(5) Lauer, J. L., Correction for light absorption in fluorescence and light scattering measurements: Opt. Soc. America Jour., v. 41, no. 7 , p. 482-483, 1951.

(6) Lothian, G. F., A photoelectric fluorimeter: Jour. Sci. Instruments, v. 18, p. 200-202, 1941.

(7) Willard, H. H., and Horton, C. A., Indicators for titration of fluoride with thorium: Anal. Chemistry, v. 22, p. 1190-1194, 1950.

(8) Willard, H. H., and Horton, C. A., Photofluorometric titration of fluoride: Anal. Chemistry, v. 22, p. 1194-1197, 1950. 
APPENDIX

Tables $3-10$ 
Table 3.--Absorptivity values for morin and the complex.

Units for $\epsilon=$ liter $/($ mole $\mathrm{cm})$, i.e., $\epsilon=$ absorbance for 1 mole/liter, $1 \mathrm{~cm}$ light path

Units for $a=50 \mathrm{ml} /($ microgram $\mathrm{cm})$, i.e., $a=$ absorbance for 1 microgram $/ 50 \mathrm{ml}, 1 \mathrm{~cm} 1$ ight path.

Exciting light $404.7 \mathrm{m \mu}$

Exciting light $365.0 \mathrm{m \mu}$

For solutions of the pure complex I/

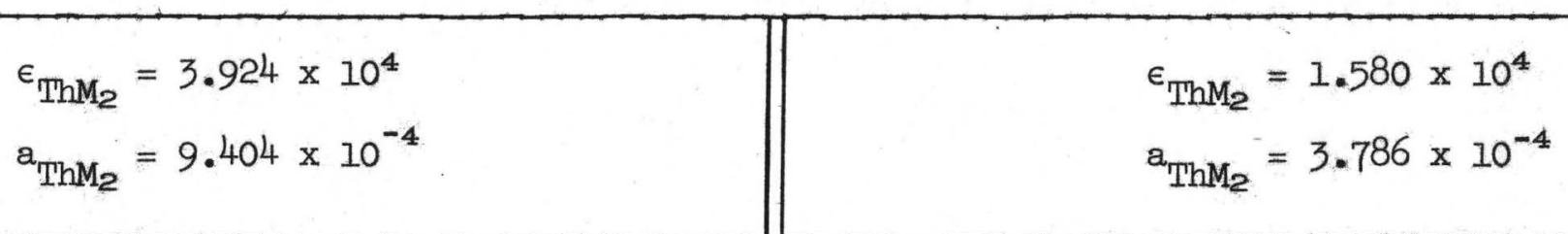

For solutions of pure morin

\begin{tabular}{c|c|c|c}
\hline $\begin{array}{c}\text { Alcohol content } \\
2 \mathrm{ml}\end{array}$ & $\begin{array}{c}\text { Alcohol content } \\
12 \mathrm{ml}\end{array}$ & $\begin{array}{c}\text { Alcohol content } \\
2 \mathrm{ml}\end{array}$ & $\begin{array}{c}\text { Alcohol content } \\
12 \mathrm{ml}\end{array}$ \\
\hline$\epsilon_{\mathrm{M} \cdot \mathrm{H}}=6.849 \times 10^{2}$ & $\epsilon_{\mathrm{M} \cdot \mathrm{H}}=8.689 \times 10^{2}$ & $\epsilon_{\mathrm{M} \cdot \mathrm{H}}=1.148 \times 10^{4}$ & $\epsilon_{\mathrm{M} \cdot \mathrm{H}}=1.367 \times 10^{4}$ \\
$\mathrm{a}_{\mathrm{M} \cdot \mathrm{H}}=4.500 \times 10^{-5}$ & $\mathrm{a}_{\mathrm{M} \cdot \mathrm{H}}=5.138 \times 10^{-5}$ & $\mathrm{a}_{\mathrm{M} \cdot \mathrm{H}}=6.79 \times 10^{-4}$ & $a_{\mathrm{M} \cdot \mathrm{H}}=8.08 \times 10^{-4}$ \\
\hline
\end{tabular}

For solutions containing excess morin in the presence of complex

$\left|\begin{array}{l}\epsilon_{\mathrm{M} \cdot \mathrm{H}_{1}}=1.045 \times 10^{3} \\ \mathrm{a}_{\mathrm{M} \cdot \mathrm{H}_{1}}=6.179 \times 10^{-5}\end{array}\right| \mid$

If Absorptivity of pure complex the same for $2 \mathrm{ml}$ and $12 \mathrm{ml}$ of alcohol. 
Table 4.-Fraction of total $\mathrm{ThO}_{2}$ (50.3 micrograms) in the form of complex, when concentration of morin ranges from 0.4000 micrograms per $50 \mathrm{ml}$.

\begin{tabular}{|c|c|c|c|}
\hline $\begin{array}{l}\text { Total morin } \\
\text { added } \\
\gamma / 50 \mathrm{ml} \\
\end{array}$ & $\begin{array}{c}\text { Uncombined } \\
\text { morin } \\
\gamma / 50 \mathrm{ml}\end{array}$ & $\begin{array}{l}\text { Complex formed } \\
\gamma / 50 \mathrm{ml}\end{array}$ & $\begin{array}{l}\text { Fraction of total } \\
\text { possible complex formed I/ }\end{array}$ \\
\hline 0 & 0. & 0. & 0 \\
\hline 5 & 3.6 & 1.68 & 0.010 \\
\hline 10 & 7.2 & 3.36 & 0.021 \\
\hline 20 & 14.5 & 6.74 & 0.042 \\
\hline 40 & 29.0 & 13.5 & 0.084 \\
\hline 60 & 43.1 & 20.8 & 0.130 \\
\hline 80 & 57.5 & 27.7 & 0.174 \\
\hline 100 & 71.6 & 34.9 & 0.219 \\
\hline 120 & 87.5 & 41.3 & 0.260 \\
\hline 140 & 102. & 47.4 & 0.298 \\
\hline 160 & 117. & 53.2 & 0.334 \\
\hline 180 & 132.4 & 58.6 & 0.368 \\
\hline 200 & 149. & 63.5 & 0.399 \\
\hline 220 & 165. & 68.1 & 0.428 \\
\hline 240 & 182. & 72.1 & 0.453 \\
\hline 260 & 198. & 76.0 & 0.478 \\
\hline 280 & 216. & 79.3 & 0.498 \\
\hline 300 & 234. & 81.7 & 0.514 \\
\hline 340 & 269. & 87.5 & 0.550 \\
\hline 380 & 305. & 93.1 & 0.585 \\
\hline 400 & 323. & 95.2 & 0.599 \\
\hline 450 & 369. & 99.9 & 0.628 \\
\hline 500 & 416. & 104.1 & 0.655 \\
\hline 600 & 510. & 111.2 & 0.700 \\
\hline 800 & 701. & 121.6 & 0.765 \\
\hline 1000 & 895. & 129.2 & 0.813 \\
\hline 1200 & 1091. & 135.0 & 0.850 \\
\hline 1400 & 1287. & 139.8 & 0.880 \\
\hline 1600 & 1483. & 144.6 & 0.909 \\
\hline 1800 & 1680. & 148.4 & 0.934 \\
\hline 2000 & 1877. & 151.3 & 0.952 \\
\hline 2200 & 2075. & 153.9 & 0.968 \\
\hline 2400 & 2276. & 155.9 & 0.981 \\
\hline 2600 & 2473. & 157.2 & 0.989 \\
\hline 3000 & 2871. & 158.6 & 0.998 \\
\hline 3200 & 3071. & 158.6 & 0.998 \\
\hline 3400 & 3271. & 158.6 & 0.998 \\
\hline 3600 & 3471. & 158.6 & 0.998 \\
\hline 4000 & 3871. & 158.6 & 0.998 \\
\hline
\end{tabular}

1) Total possible complex $=158.9$ micrograms. 
Table 5.- Fraction of total fluorescence remaining unquenched when 50.3 micrograms $\mathrm{ThO}_{2}$ is mixed with amounts of morin ranging from 0.600 micrograms per $50 \mathrm{ml}$ ( $2 \mathrm{ml}$ of alcohol per $50 \mathrm{ml}$ of solution).

\begin{tabular}{ccccc}
\hline $\begin{array}{c}\text { Total morin } \\
\gamma / 50 \mathrm{ml}\end{array}$ & $\begin{array}{c}\text { Uncombined } \\
\text { morin } \\
\gamma / 50 \mathrm{ml}\end{array}$ & $\begin{array}{c}\text { Total possible } \\
\text { fluorescence } \\
(1 . \text { scale) } \\
\text { I) }\end{array}$ & $\begin{array}{c}\text { Fluorescence } \\
\text { measured } \\
\text { (1. scale) }\end{array}$ & $\begin{array}{c}\text { Fraction of } \\
\text { fluorescence } \\
\text { unquenched }\end{array}$ \\
\hline 0 & 0. & 0. & 0. & \\
5 & 3.64 & 0.0382 & 0.042 & 1.10 \\
10 & 7.27 & 0.0729 & 0.072 & 0.987 \\
20 & 14.5 & 0.147 & 0.152 & 1.03 \\
40 & 29.1 & 0.284 & 0.292 & 1.03 \\
60 & 43.2 & 0.426 & 0.367 & 0.861 \\
80 & 57.5 & 0.550 & 0.418 & 0.761 \\
100 & 71.7 & 0.678 & 0.437 & 0.645 \\
120 & 87.5 & 0.780 & 0.454 & 0.582 \\
140 & 102. & 0.876 & 0.458 & 0.523 \\
160 & 117. & 0.965 & 0.459 & 0.476 \\
180 & 133. & 1.03 & 0.454 & 0.439 \\
200 & 149. & 1.10 & 0.438 & 0.397 \\
220 & 165. & 1.15 & 0.423 & 0.365 \\
240 & 182. & 1.20 & 0.403 & 0.334 \\
260 & 198. & 1.25 & 0.383 & 0.306 \\
280 & 216. & 1.28 & 0.367 & 0.286 \\
300 & 234. & 1.30 & 0.350 & 0.269 \\
340 & 269. & 1.36 & 0.319 & 0.234 \\
380 & 305. & 1.42 & 0.290 & 0.204 \\
400 & 323. & 1.44 & 0.280 & 0.194 \\
450 & 369. & 1.46 & 0.251 & 0.172 \\
500 & 416. & 1.46 & 0.227 & 0.156 \\
600 & 510. & 1.47 & 0.187 & 0.127 \\
& & & &
\end{tabular}

If Total possible fluorescence $=\left(\frac{a_{3} c_{3}}{a_{2} c_{2}+a_{3} c_{3}}\right)\left(\mathrm{KP}_{0}\right)\left(1-10^{-A}\right)$ $K P_{0}=3.17$ (1. scale). 
Table 6.--Fraction of total fluorescence remaining unquenched when 50.3 micrograms $\mathrm{ThO}_{2}$ is mixed with amounts of morin ranging from $0-4000$ micrograms per $50 \mathrm{ml}$ of solution ( $12 \mathrm{ml}$ of alcohol per $50 \mathrm{ml}$ of solution).

\begin{tabular}{|c|c|c|c|c|}
\hline $\begin{array}{l}\text { Total morin } \\
\gamma / 50 \mathrm{ml}\end{array}$ & $\begin{array}{l}\text { Uncombined } \\
\text { morin } \\
\gamma / 50 \mathrm{ml}\end{array}$ & $\begin{array}{l}\text { Total possible } \\
\text { fluorescence } \\
\text { (1. scale) I/ }\end{array}$ & $\begin{array}{l}\text { Fluorescence measured } \\
\text { (corrected. for blank) } \\
\text { (1. scale) }\end{array}$ & $\begin{array}{l}\text { Fraction } \\
\text { fluoresce } \\
\text { unquench }\end{array}$ \\
\hline 0 & & & & \\
\hline 5 & 3.64 & & & \\
\hline 10 & 7.27 & & & \\
\hline 20 & 14.5 & 0.235 & 0.232 & 0.987 \\
\hline 40 & 29.1 & 0.462 & 0.452 & 0.979 \\
\hline 60 & 43.2 & 0.690 & 0.562 & 0.814 \\
\hline 80 & 57.5 & 0.892 & 0.682 & 0.764 \\
\hline 100 & 71.7 & 1.10 & 0.852 & 0.775 \\
\hline 120 & 87.5 & 1.28 & 0.957 & 0.750 \\
\hline 140 & 102. & 1.42 & 1.00 & 0.703 \\
\hline 160 & 117. & 1.56 & 1.03 & 0.658 \\
\hline 180 & 133. & 1.69 & 1.03 & 0.608 \\
\hline 200 & 149. & 1.79 & 1.03 & 0.575 \\
\hline 220 & 165. & 1.90 & 1.03 & 0.542 \\
\hline 240 & 182. & 1.97 & 0.992 & 0.503 \\
\hline 260 & 198. & 2.05 & 0.972 & 0.474 \\
\hline 280 & 216. & 2.11 & 0.942 & 0.447 \\
\hline 300 & 234. & 2.14 & 0.920 & 0.431 \\
\hline 340 & 269. & 2.24 & 0.874 & 0.391 \\
\hline 380 & 305. & 2.32 & 0.822 & 0.354 \\
\hline 400 & 323. & 2.36 & 0.794 & 0.336 \\
\hline 450 & 369. & 2.44 & 0.739 & 0.304 \\
\hline 500 & 416. & 2.45 & 0.677 & 0.276 \\
\hline 600 & 510. & 2.51 & 0.585 & 0.233 \\
\hline 800 & 701. & 2.59 & 0.463 & 0.179 \\
\hline 1000 & 895. & 2.57 & 0.378 & 0.147 \\
\hline 1200 & 1091. & 2.56 & 0.315 & 0.123 \\
\hline 1400 & 1287. & 2.54 & 0.267 & 0.105 \\
\hline 1600 & 1483. & 2.51 & 0.228 & 0.091 \\
\hline 1800 & 1680. & 2.46 & 0.196 & 0.080 \\
\hline 2000 & 1877. & 2.42 & 0.171 & 0.071 \\
\hline 2200 & 2075. & 2.38 & 0.151 & 0.063 \\
\hline 2400 & 2276. & 2.32 & 0.135 & 0.058 \\
\hline 2600 & 2473. & 2.26 & 0.122 & 0.054 \\
\hline 3000 & 2871. & 2.14 & 0.103 & 0.048 \\
\hline 3200 & 3071. & 2.08 & 0.096 & 0.046 \\
\hline 3400 & 3271. & 2.02 & 0.089 & 0.044 \\
\hline 3600 & 3471. & 1.97 & 0.084 & 0.043 \\
\hline 4000 & 3871. & 1.86 & 0.075 & 0.040 \\
\hline
\end{tabular}

$\mathrm{KP} O=1 / \mathrm{Total}$ possible fluorescence $=\left(\frac{a_{3} c_{3}}{a_{2} c_{2}+a_{3} c_{3}}\right)(\mathrm{KPo})\left(1-10^{-\mathrm{A}}\right)$ 
Table 7.--Calculated fluorescence for solutions containing a total of 50.3 micrograms $\mathrm{ThO}_{2}$, and amounts of morin ranging from 50-200 micrograms per $50 \mathrm{ml}$ (2 ml of alcohol per $50 \mathrm{ml}$ of solution).

\begin{tabular}{lcl}
$\begin{array}{c}\text { Total } \mathrm{ThO}_{2} \\
\gamma / 50 \mathrm{ml}\end{array}$ & $\begin{array}{c}\text { Uncombined morin } \\
\gamma / 50 \mathrm{ml}\end{array}$ & $\begin{array}{c}\text { Calculated } \\
\text { fluorescence } \\
\text { (1. scale) }\end{array}$ \\
\hline 50.3 & 50 & 0.394 \\
50.3 & 60 & 0.421 \\
50.3 & 70 & 0.436 \\
50.3 & 80 & 0.457 \\
50.3 & 90 & 0.466 \\
50.3 & 100 & 0.473 \\
50.3 & 110 & 0.468 \\
50.3 & 120 & 0.462 \\
50.3 & 130 & 0.452 \\
50.3 & 140 & 0.444 \\
50.3 & 150 & 0.436 \\
50.3 & 160 & 0.424 \\
50.3 & 170 & 0.411 \\
50.3 & 180 & 0.406 \\
50.3 & 190 & 0.395 \\
50.3 & 200 & 0.388 \\
& &
\end{tabular}


Table 8.--Caleulated fluorescence for solutions containing a total of 15 micrograms of $\mathrm{ThO}_{2}$ and amounts of morin ranging from $50-200$ micrograms of morin per $50 \mathrm{ml}$ ( $2 \mathrm{ml}$ of alcohol per $50 \mathrm{ml}$ of solution).

\begin{tabular}{lcl}
\hline $\begin{array}{c}\text { Total } \mathrm{ThO}_{2} \\
\gamma / 50 \mathrm{ml}\end{array}$ & $\begin{array}{c}\text { Uncombined morin } \\
\gamma / 50 \mathrm{ml}\end{array}$ & $\begin{array}{c}\text { Calculated } \\
\text { fluorescence } \\
\text { (1. scale) }\end{array}$ \\
\hline 15 & 70 & 0.1403 \\
15 & 75 & 0.1532 \\
15 & 80 & 0.1560 \\
15 & 85 & 0.1586 \\
15 & 90 & 0.1599 \\
15 & 100 & 0.1611 \\
15 & 110 & 0.1616 \\
15 & 120 & 0.1618 \\
15 & 125 & 0.1614 \\
15 & 130 & 0.1596 \\
15 & 140 & 0.1574 \\
15 & 150 & 0.1572 \\
15 & 170 & 0.1550 \\
15 & 200 & 0.1482 \\
15 & & 0.1412 \\
& &
\end{tabular}


Table 9.--Calculations of complex formed (micrograms per $50 \mathrm{ml}$ ) for solutions containing, (a) a total of 100 micrograms morin and $\mathrm{ThO}_{2}$ ranging from 10 to 60 micrograms, (b) a total of 165 micrograms morin and $\mathrm{ThO}_{2}$ ranging from 10 to 90 micrograms.

Total morin $\gamma / 50 \mathrm{ml}$
Total $\mathrm{ThO}_{2}$ $\gamma / 50 \mathrm{ml}$
$\mathrm{K}_{\mathrm{E}}$ used in

calculations

$1.39 \times 10^{+6}$

$1.41 \times 10^{+6}$

$1.44 \times 10^{+6}$

$1.48 \times 10^{+6}$

$1.524 \times 10^{+6}$

$1.57 \times 10^{+6}$

$1.61 \times 10^{+6}$
Complex formed. $\gamma / 50 \mathrm{ml}$

9.0

13.5

17.2

24.3

29.3

34.9

39.3

(b)

165

165

165

165

165

165

165

165

165

165

165
10

15

20

30

40

45

50

60

70

80

90
$0.850 \times 10^{+6}$

$0.875 \times 10^{+6}$

$0.90 \times 10^{+6}$

$0.950 \times 10^{+6}$

$1.0 \times 10^{+6}$

$1.025 \times 10^{+6}$

$1.05 \times 10^{+6}$

$1.10 \times 10^{+6}$

$1.15 \times 10^{+6}$

$1.20 \times 10^{+6}$

$1.25 \times 10^{+6}$
12.8

18.9

24.1

36.3

46.0

51.2

54.8

63.0

70.9

78.2

84.1 
Table 10.--Calculated fluorescence for standard curves--100-165 micrograms of morin per $50 \mathrm{ml}$ ( $2 \mathrm{ml}$ of alcohol per $50 \mathrm{ml}$ of solution).

\begin{tabular}{|c|c|c|}
\hline $\begin{array}{l}\text { Total morin } \\
\gamma / 50 \mathrm{ml}\end{array}$ & $\begin{array}{c}\text { Total } \mathrm{ThO}_{2} \\
\gamma / 50 \mathrm{ml}\end{array}$ & $\begin{array}{l}\text { Calculated } \\
\text { fluorescence- } \\
\text { (1. scale) }\end{array}$ \\
\hline 100 & 10 & 0.106 \\
\hline 100 & 15 & 0.161 \\
\hline 100 & 20 & 0.208 \\
\hline 100 & 30 & 0.300 \\
\hline 100 & 40 & 0.372 \\
\hline 100 & 50 & 0.445 \\
\hline 100 & 60 & 0.511 \\
\hline 165 & 10 & 0.102 \\
\hline 165 & 15 & 0.153 \\
\hline 165 & 20 & 0.197 \\
\hline 165 & 30 & 0.292 \\
\hline 165 & 40 & 0.372 \\
\hline 165 & 45 & 0.424 \\
\hline 165 & 50 & 0.459 \\
\hline 165 & 60 & 0.533 \\
\hline 165 & 70 & 0.612 \\
\hline 165 & 80 & 0.686 \\
\hline 165 & 90 & 0.751 \\
\hline
\end{tabular}

